\title{
A Novel Automated Design Methodology for Power Electronics Converters
}

\author{
André Andreta ${ }^{1, *(\mathbb{D})}$, Luiz Fernando Lavado Villa ${ }^{2}(\mathbb{D})$, Yves Lembeye ${ }^{1}(\mathbb{D})$ and Jean Christophe Crebier ${ }^{1}$ \\ 1 Grenoble Electrical Engineering Laboratory, National Centre for Scientific Research, \\ Grenoble Institute of Technology, Université Grenoble Alpes, 38000 Grenoble, France; \\ Yves.Lembeye@g2elab.grenoble-inp.fr (Y.L.); jean-christophe.crebier@grenoble-inp.fr (J.C.C.) \\ 2 Laboratory for Analysis and Architecture of Systems, National Centre for Scientific Research, \\ University of Toulouse, 31031 Toulouse, France; luiz.villa@laas.fr \\ * Correspondence: andre.andreta@g2elab.grenoble-inp.fr
}

Citation: Andreta, A.; Lavado Villa, L.F.; Lembeye, Y.; Crebier, J.C. A Novel Automated Design Methodology for Power Electronics Converters. Electronics 2021, 10, 271. https://doi.org/10.3390/ electronics10030271

Academic Editor: Gabriele Grandi

Received: 15 December 2020

Accepted: 20 January 2021

Published: 23 January 2021

Publisher's Note: MDPI stays neutral with regard to jurisdictional claims in published maps and institutional affiliations.

Copyright: (c) 2021 by the authors. Licensee MDPI, Basel, Switzerland. This article is an open access article distributed under the terms and conditions of the Creative Commons Attribution (CC BY) license (https:// creativecommons.org/licenses/by/ $4.0 /)$.
Abstract: This work proposes a methodology for designing power electronic converters called "Automatic Design for Manufacturing" (ADFM). This methodology proposes creating Power Converter Arrays (PCAs) using standardized converter cells. The approach is greatly inspired by the microelectronics integrated circuit design flow, power electronics building blocks, and multicell converters. To achieve the desired voltage/current specifications, the PCA conversion stage is made from the assembly of several Conversion-Standard Cells (CSCs) in series and/or parallel. The ADFM uses data-based models to simulate the behavior of a PCA with very little computational effort. These models require a special characterization approach to maximize the amount of knowledge while minimizing the amount of data. This approach consists of establishing an experiment plan to select the relevant measurements that contain the most information about the PCA technology, building an experimental setup that is capable of acquiring data automatically and using statistical learning to train models that can yield precise predictions. This work performed over $210 \mathrm{~h}$ of tests in nine different PCAs in order to gather data to the statistical models. The models predict the efficiency and converter temperature of several PCAs, and the accuracy is compared with real measurements. Finally, the models are employed to compare the performance of PCAs in a specific battery charging application.

Keywords: multicell converters; power converter array; automatic design; statistical modeling; Gaussian process model; power electronic building blocks

\section{Introduction}

Design automation in power electronics is a topic that has received much attention in the past years. The main motivations behind the topic are the shortening of product development cycles, the increased use of highly complex power converters, and also the improvement of robustness, resilience, and reliability [1,2].

The automatic design process in power electronics is a hot topic and is discussed today in several research groups around the world [2]. For example, in [3], tools are proposed for assisting the designer choices such as the converter topology selection, the magnetic components design, switching frequency tune, etc. An optimal solution can be obtained with reduced modeling and simulation efforts. Likewise, [4] presents tools for assisting the designer to select the optimal topology, switching frequency, and even the exact components that should be used in order to achieve an optimal solution. In [5], the authors introduce design automation for power modules. The focus of these design methods is on assisting the designer to perform good/optimal decisions during the converter design and to accelerate the design process. However, neither proposes a straightforward automatic process starting from some converter specification to an industrialized product by a com- 
plete automatic procedure. In particular, the implementation itself toward manufacture remains most of the time to be done, together with the industrialization process.

Computer-Aided Design still struggles against the lack of standardization in Power Electronics [1]. The sheer number of possible topologies to be considered, together with the amount of components that can be employed to perform exactly the same function and the whole converter design process is so heterogeneous that it is difficult to consider all the parameters and variables that must be considered to accomplish a complete design to manufacture. This is precisely the starting point of the ADFM method proposed in this paper: to contribute to introduce standardization with the objective to perform a fully automated design for manufacturing in Power Electronics.

The Automatic Design for Manufacturing (ADFM) has three main sources of inspiration: The Power Electronic Building Blocks (PEBB), the muticell converters, and the microelectronic digital integrated circuit design process. The ADFM totally rethinks what a power converter is and how to create one. The proposed method sees a power converter as the assembly of standard components rather than a complex design process of a unique solution.

The Power Electronics Building Block (PEBB) methodology formalized the idea that reliability can be improved while reducing costs by using standard building blocks in the design of power electronics converters [6-12]. The methodology streamlined the conception of converters with high power density, efficiency, and reliability [13,14]. It achieved scalability, high voltage operation, repairability, and reliability. Nevertheless, the idea of an automated design process and the missing link between microelectronic and power electronics, which were pursued in its initial publications [6], are less present in its actual state of the art. The most notable low and medium power/voltage converters based on standardized subsystem are the power modules and IPEM (Integrated Power Electronics Modules) [15,16].

Multicell converter topologies and architectures give also inspiration to the automated design of power electronic converters. The "multicell" terminology was first employed in the 1990s, as illustrated in $[17,18]$ to call for what today is named a flying capacitor converter. The technique was initially focused on performing high-voltage power conversion and started to be implemented in multiple high-power applications [19]. In the early 2000s, "multicell converter" was also referring to any converter topology made out several conversion cells [20]. More recently, thanks to the increase in performances and characteristics of low-voltage power devices such as MOSFETS but also wide band gap devices, and their associated gate driver stages, multicell converters are also implemented in medium and low-voltage applications to benefit from the multicell properties to design more efficient converters [21].

The ADFM method proposes combining PEBB principles and multicell converters conversion techniques with microelectronic digital integrated circuit design and manufacturing workflow. Digital electronics design and manufacturing flows have allowed creating very complex systems and devices, integrating in one single chip billions of transistors while providing extremely high levels of reliability, constrained costs, and overall production efficiency. Despite the differences between microelectronics and power electronics, the digital synthesis approach, based on the automated and generic association of standardized cells, offers a great illustration of how power electronics converters design methods could be inspired.

In contrast with most of the methods presented in [1], the ADFM method does not aim to create an optimal solution for a converter. Instead, it proposes a viable solution, with a reliable prediction of efficiency and operating temperature. The performance levels of the designed converter are not defined by a careful optimization at converter-level design but by an overall optimization of the technology platform (TP) characteristics, which are in turn used in the converter design process [22,23].

The contribution of this paper lies in presenting the main steps of the ADFM methodology and the process it follows to automatically create a power converter. Another important achievement of the ADFM method is the accurate prediction of the performance 
(efficiency and temperature) of converters through virtual prototyping. This paper details the construction of statistical models based on machine learning algorithms to predict the converter's performance and how to acquire a relevant dataset to train these algorithms. The statistical models can be used to determine the performance of a converter in every point of operation of a mission profile. For that purpose, the presented work assumes that a technology platform is already available, containing all necessary standard cells to build a PCA. In such a sense, the paper is not focused on the optimization of the PCA performances or characteristics. It is strictly focused on the design method and then selects the best compromises from a set of possible solutions.

This paper is organized as follows. Section 2 briefly introduces the technology platform concept, through its analogy with digital electronics design flow. Section 3 describes in detail the ADFM methodology to create a power converter from standard cells. In order to acquire knowledge on the standardized cells, which the methodology assembles to create converters, there is a long process of characterization and construction of a database. The main steps of this process are presented in Section 3. Once the data that describes the standard cells, as well as their associations, are acquired, Section 4 presents the machine learning algorithms used to train statistical models describing the main characteristics of any PCA designed from these standard cells. Section 5 presents some practical use of the models, which were used to predict the behavior of the converters created by the ADFM methodology, at any operating points.

\section{The Technology Platform}

In a comparable process with digital design in microelectronics, the ADFM method in power electronics consists in assembling and interconnecting standard cells to create Power Converter Arrays (PCA). A PCA is an assembly of well-known and reliable standardized elements, or Standard Cells (SC). These standard cells are constructed within a technology framework, which follows a rigorous maturation process that ensure an optimal performances and industrialization readiness. The PCA can be divided in two parts: a power conversion stage and a control stage.

The power conversion stage of a PCA is made by the assembly of Conversion-SCs (CSC) associated with Terminal-SCs (TSC), corresponding respectively to the front end and the back end in microelectronics. The SC cannot be modified from one design to another, so, the way these cells are physically arranged and electrically interconnected are used to determine the power electronics work function (step up, step down, multiple outputs, single three, or multiphase conversion). A variety of CSCs are needed to answer the various functions to be implemented in power electronics (DC to DC, AC to DC, bidirectional current, galvanic isolation or not, etc.). In addition, the same technology platform may integrate several CSC families with the same functionalities but for different voltage or current ratings.

In order to create PCAs with different voltage and current conversion ratios, CSCs are associated in four different types of configurations: Input series output series (ISOS), input series output parallel (ISOP), input parallel output series (IPOS), and input parallel output parallel (IPOP). Figure 1 (left) presents the schematic of a PCA made from eight CSCs, which were connected with three levels of configuration. The physical arrangement, which in the context of this work is named architecture, can be made in lines, columns, and/or boards, as presented in Figure 1 (right).

The "control" stage contains Measurement-SCs (MSC), Protection-SCs (PSC), and Control-SC (CoSC). The SCs presented in the control stage are highly dependent on the application, on how many measurements are required (voltage and/or current), the type of protection, etc. Details about the control stage SCs are out of the scope of this publication. 

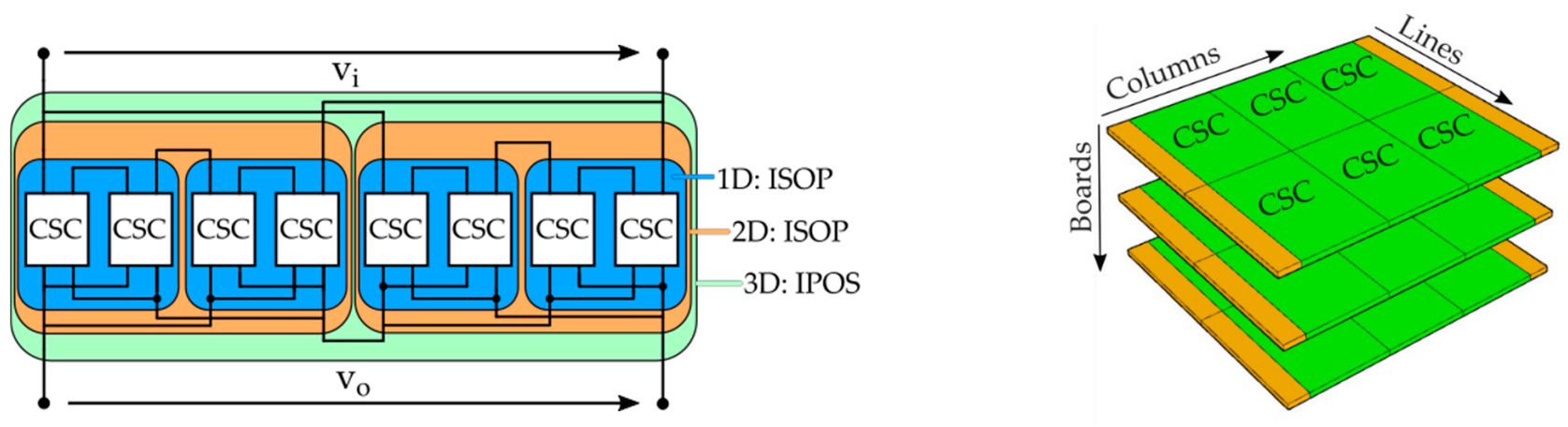

Figure 1. The concept of configuration and architecture in Automatic Design for Manufacturing (ADFM). (Left): The schematic of a Power Converter Array (PCA) made from eight Conversion-Standard Cells (CSCs) that illustrate the concept of configuration. The figure shows the electrical connections of three dimensions of configuration. (Right): The physical arrangement of a PCA made from 18 CSCs, illustrating the concept of architecture.

The specifications of a technology platform are always larger than the one of a specific converter. It includes a set of generic characteristics, such as standard and regulation compliance, some technology constraints, such as available cooling, interconnection, and assembly techniques, some performances goals such as targets on space for which design of PCA are possible, such as the range in input/output voltages and currents, range in dynamics, etc.

ADFM automated design uses algorithms to find solutions to configure and to assemble the various standard cells necessary to fulfill some given converter specifications. Similar to the microelectronic integrated circuit synthesis, the models that describe how families of SCs behave are data-driven statistical models based in real experiments. The creation of these models is presented in the following sections of this work.

\section{The Automated Design for Manufacturing (ADFM) Method}

Power electronic converters are traditionally designed following several steps as presented in Figure 2, the steps consist of the following:

Defining the converter specifications: The converter specifications must be clear, well defined, and evaluated and approved by the lead designer as a feasible request. All specifications, including the function to be performed, power and/or current and/or voltage levels, expected dynamics, the converter operating conditions such as ambient temperature, and ambient thermal cycling are fundamental. It also includes application field requirements such as efficiency, power quality, power density, price, complexity, and standards compliance.

Converter Design: The designer chooses the circuit topology, the modulation scheme, the control strategy, and the types and ratings of the components together with the switching frequency. An important issue is related to the interconnect and assembly technologies to be chosen together with the cooling. These choices have a significant impact on converter performances and characteristics such as power densities or efficiency. Then, the designer must take care of the physical arrangements of the converter and the positions of the components. Housing, cooling techniques, and packaging must be defined according to operating and implementation conditions. This stage also includes electrical and/or thermic simulations to tune some design parameters.

Prototype: A prototype is usually built and implemented to verify if the design and choices are in accordance with the specifications and the targeted performances. If the specifications are not achieved, or if the performances are below expectations, the designer must take some steps back and carry on a rework on the design itself and the decisions made.

Industrialization: The industrialization process purpose is to verify the component selections and sourcing to achieve lower costs and higher availability. The manufacturing complexity is verified, and the layout and position of components may be modified to ease the assembly process. In addition, tests to evaluate the converter reliability are performed. 
Accelerated aging tests are made to verify that it complies with specifications over a certain period of time.

Standard compliance: Then, the power electronic (PE) converter must be tested for standard and regulation compliance before entering in mass production.

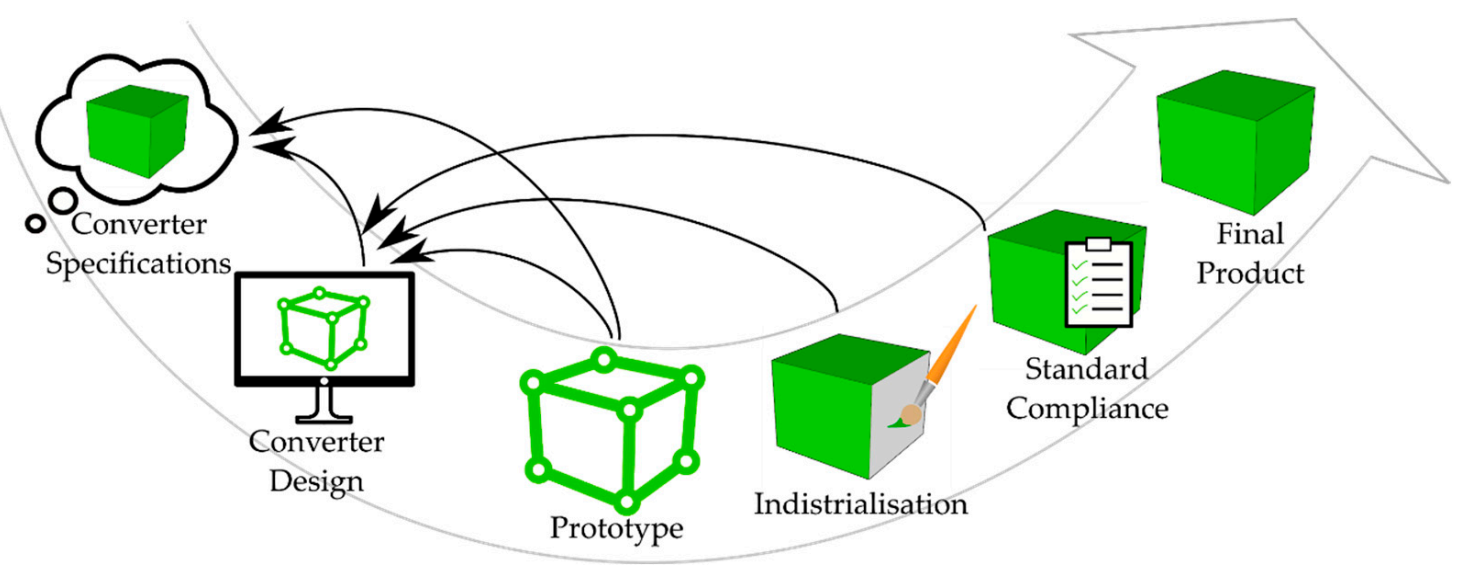

Figure 2. Power converter traditional design flow.

Once this process is completed, the price for the PE converter can be set. Its main characteristics can be accurately determined, such as its power density, efficiency, and reliability.

As it has been described above, the design process of a PE converter is a complicated and multidisciplinary process. Several tools have been developed to help in the design process. Among them, circuit and control simulation software are specific and essential. In addition, multi-physics software such as thermal and fluid simulation, finite element modeling, and electromagnetic interference analysis are regularly considered to help the designer in its optimization process. Nonetheless, the full design process requires many hours of work, involving various specialists from different fields. As a matter of fact, the design process of a brand-new converter is expensive and time consuming.

In opposition to the traditional method, the ADFM presented in Figure 3 proposes a completely inverse logic to design a converter. Prior to running a complete ADFM, a set of technology platforms must be made available to cover a wide range of options, applications, and targeted performances. Once each of these technology platforms are well characterized and modeled, a database is built for each of them with many parameters and characteristics made available for the design and selection routine. Based on machine learning and statistical modeling, the characteristics are extracted from existing and representative PCAs and CSCs, providing accurate prediction models.

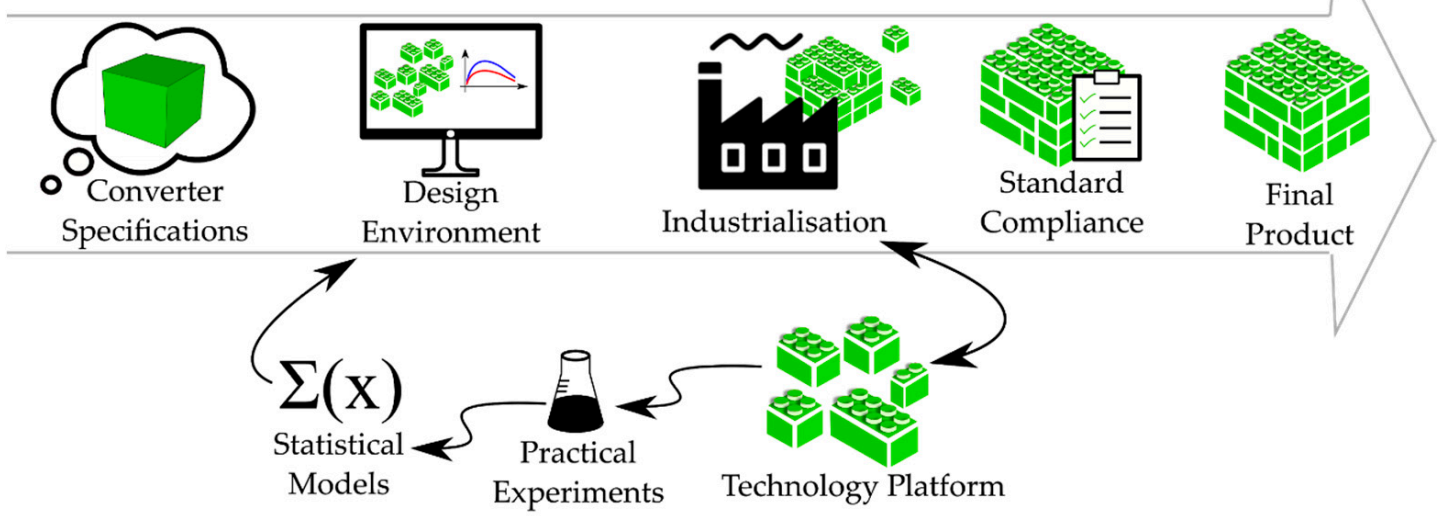

Figure 3. Automatic Design for Manufacturing (AFDM) design flow. 
Based on these highly accurate models, a very linear and straightforward design and selection approach can be carried out from the specifications of the desired power converter through a virtual prototyping phase. First, the converter specifications are compared to the characteristics of each technology platform. Then, possible solutions are identified in each phase of the TP compliance. Various configurations and architectures are virtually prototyped to identify the one with the best characteristics. In the space of all possible solutions, the designer tunes the design and selection parameters to identify the best option to be afterwards produced. Since all this process is only able to select interconnections and assemble standardized cells that are built to be interconnected and assembled, there is no custom design carried out. The resulting PCA converter is the optimal solution that the given TP can provide. The virtual prototyping phase also allows knowing in advance that it will be possible to produce it in volume, and it is also possible to predict accurately its main characteristics such as efficiency, power densities, thermal cooling needs, and even compliance with regulations. It is expected with such a design approach to be able to run a first prototype that will directly meet all specifications as long as these specifications are feasible under the TP characteristics.

This paper is now going to focus on the characterization stage of the power part of the PCA, with the objective to tune predictive models able to forecast efficiency and converter temperature with respect to specifications, which are the cornerstone of the virtual prototyping that the proposed method is built upon.

\section{Design of the Experiments and Experimental Setup}

The ADFM method presented in this paper uses two figures of merit as design and selection criteria for PCAs: efficiency and the thermal characteristics. The thermal behavior of a PCA can be represented by its global operating temperature. The PCA operating temperature is directly related to generated losses and heat removal capabilities that need to be set. Operating temperature and efficiency are linked by PE converter losses, making both of them critical output variables to be considered by the designer to create a converter that will comply as much as possible with the specifications.

The input variables that affect the output variables were divided in two groups: the operating point variables (voltages, currents, cooling parameters such as ambient temperature and airflow rate) and the construction variables (architecture and configuration), as they were defined in Section 2. While dealing with multi-dimensional experiments, a commonly used procedure is a design of experiments (DOE). A DOE aims to define experiments to be carried out with the objective to maximize the amount of information gathered for a given experimental effort [24]. This work decided to apply DOE techniques individually to the operating point variables and to the construction variables because the former group can be easily studied with a prototype and the latter consists of building up different prototypes. An overview of all the input and output variables is presented in Figure 4 .

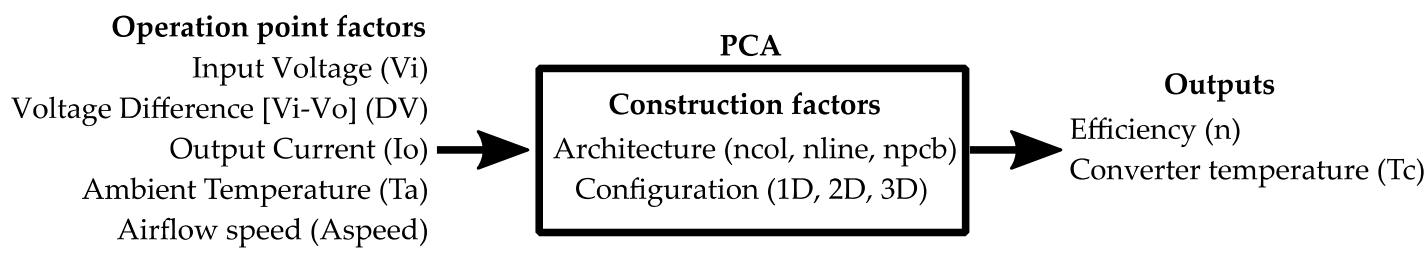

Figure 4. Input and output variables.

A technology platform is designed to cover a range of electrical and thermal specifications of certain application field. The TP studied in this work is designed to cover the range presented in Table 1. Details about the Conversion-Standard Cell studied in this work are presented in Table 2. It consists of a Dual Active Bridge topology, operating with phase shift modulation, as illustrated in Figure 5. 
Table 1. The Technology Platform main characteristics.

\begin{tabular}{cc}
\hline Parameter & Value/Detail \\
\hline Input and Output Voltage Range & $12 \mathrm{~V}$ to $600 \mathrm{~V}$ \\
Current Range & Up to $90 \mathrm{~A}$ \\
Dielectric Isolation & $1.5 \mathrm{kV}$ \\
Assembly and Interconnection Technology & $\mathrm{PCB}$ \\
Cooling Technology & Natural convection or forced air \\
\hline
\end{tabular}

Table 2. Details about the Conversion-Standard Cell (CSC) used in this work.

\begin{tabular}{cc}
\hline Parameter & Value \\
\hline Maximum Input Voltage & $20 \mathrm{~V}$ \\
Minimum Input Voltage & $8 \mathrm{~V}$ \\
Maximum Output Voltage & $20 \mathrm{~V}$ \\
Minimum Output Voltage & $8 \mathrm{~V}$ \\
Maximum Output Current & $5 \mathrm{~A}$ (Highly dependent on cooling factor) \\
Dimensions (Length, Width, Height) & $(24 \mathrm{~mm}, 47 \mathrm{~mm}, 13 \mathrm{~mm})$ \\
Insulation & $1.5 \mathrm{kV}$ \\
Weight & $30 \mathrm{~g}$ \\
PCB Maximum Temperature & $90^{\circ} \mathrm{C}$ \\
\hline
\end{tabular}

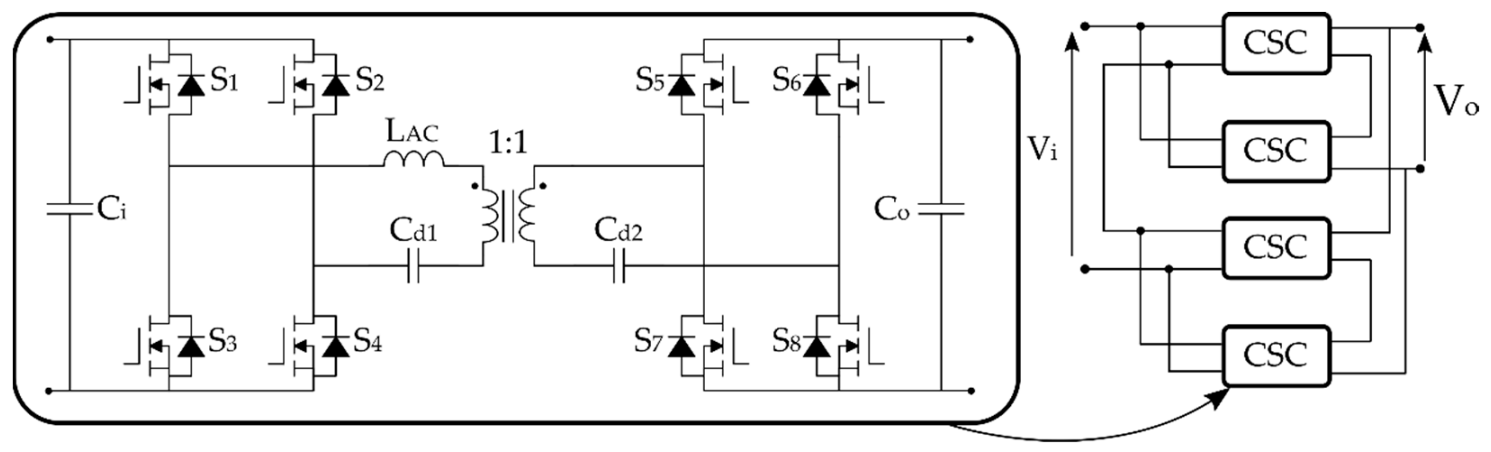

Figure 5. The Dual Active Bridge topology was used as the conversion standard cell in this work.

\subsection{Preliminary Study of the Operating Point Variables}

The two output variables that will be analyzed for every operating point of every possible PCA are the PCA efficiency and PCA maximum operating temperature. After a theoretical overview of which variables impact the efficiency and the temperature of the converter, this work defined the operation point of the PCA with five input variables: Output Current (Io), Input Voltage (Vi), Output voltage (Vo), Ambient Temperature (Ta), and Airspeed flowing through the converter (Aspeed).

In order to create a DOE, a primary set of tests was performed with three identical PCAs containing one CSC. These tests consisted in varying one variable at the time in order to identify the shape of the response each input variable induces in each output variable. Once the shapes of the responses are known, it is possible to select a minimum quantity of values for each input variable in order to set up a DOE that is accurate and representative enough of the tendencies.

Figures 6 and 7 present the results of this primary set of tests. The variable Output Voltage (Vo) is expressed by DV, which is the difference between the input voltage and the output voltage (Vi-Vo). 

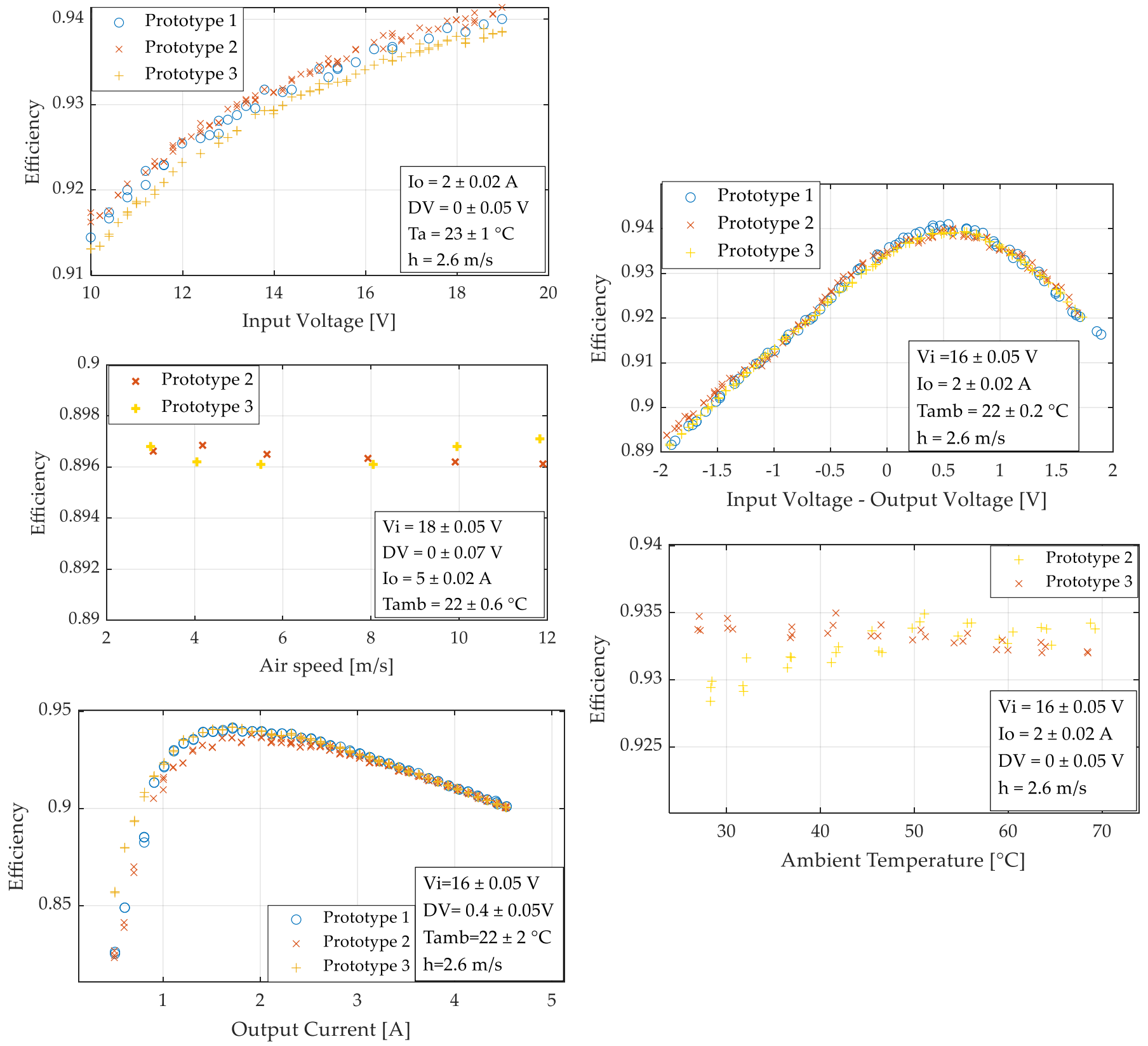

Figure 6. Experimental results of the efficiency during the "one variable at a time" test with three identical prototypes. The $x$-axis presents the input variable, which was varied during the test, while the box presents the values in which the other four input variables were fixed and their variance during the tests. 

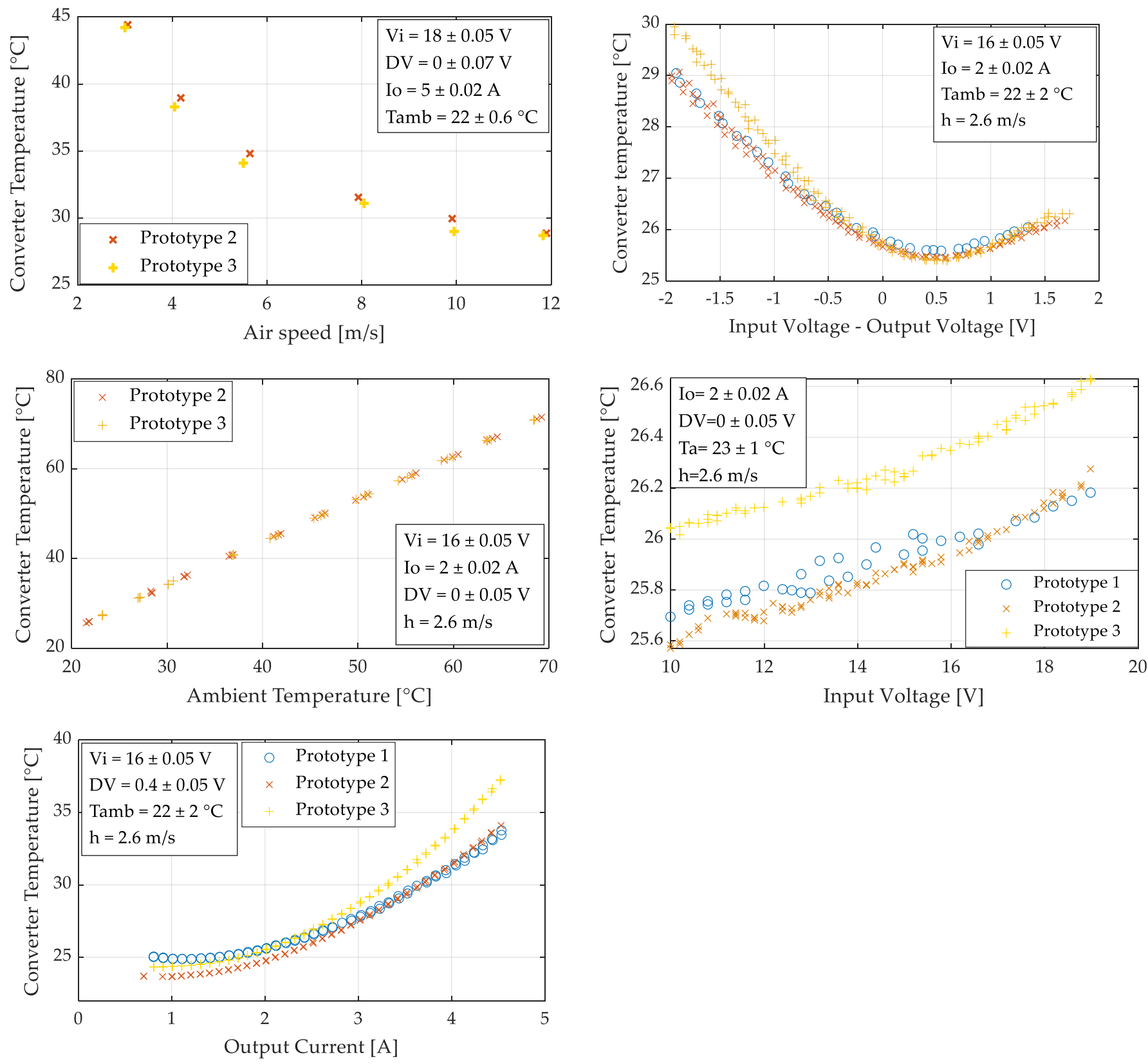

Figure 7. Experimental results of the converter temperature during the "one variable at a time" test with three identical prototypes. The $x$-axis presents the input variable, which was varied during the test, while the box presents the values in which the other four input variables were fixed and their variance during the tests.

To decide how many levels an input variable should have in the DOE, the general response of each output variable with respect to each input variable must be interpreted. Roughly, three types of responses are expected: a linear, a quadratic, or a more complex response. A linear response can be easily modeled by two levels. A quadratic can be represented by three levels. A more complex response should be modeled with four or more levels. In order to extract as much information as possible about the behavior of the variables, the levels must be selected around maximum, minimum, or inflexion points [24].

After analyzing the results of the experiments presented in Figures 6 and 7, the levels for each input variable selected are presented in Table 3. 
Table 3. Operating points in which the PCAs will be tested in a full factorial experiment.

\begin{tabular}{cccccc}
\hline \multicolumn{7}{c}{ Operating Point Study } \\
\hline Variable & Vi [V] & DV [V] & Io [A] & Aspeed [m/s] & Tamb [ $\left.{ }^{\circ} \mathbf{C}\right]$ \\
\hline $\begin{array}{c}\text { Range of variation } \\
\begin{array}{c}\text { Chosen operating } \\
\text { point }\end{array}\end{array}$ & 10 to 20 & -2 to 2 & 0 to 5 & 0 to 12 & 20 to 70 \\
& {$[10 ; 14 ; 18]$} & {$[-1 ; 0 ; 0.5 ; 1 ; 1.5]$} & {$[0.75 ; 1.5 ; 2 ; 3.5]$} & {$[2 ; 4 ; 8]$} & {$[30 ; 55]$} \\
\hline
\end{tabular}

Opposed to the experiment "one variable at a time", a full factorial test consists in testing all possible combinations among the selected levels. The individual effects of each input variable over each output variable are extracted. In addition, the coupling effects of two or more variables over each output variable can be highlighted. Table 1 summarizes the main levels selected for the first experience. With these selected points, the factorial test results in 360 experimental points to be carried out.

\subsection{Construction Variables}

Prototypes are expensive. However, construction variables are totally dependent on the hardware itself to reflect the effect of architecture and interconnection. Then, the DOE must indicate the minimum number of prototypes that best reflect these variables.

The prototypes have been built in order to enable different PCA configurations with the same hardware, acting on the power interconnections with jumpers. In such a way, the DOE can be divided into sequences: defining which prototypes to be manufactured to set the studied "architectures" and defining which power interconnections to be made in order to take into account various configurations.

As presented in Figure 1, the architecture consists of three variables representing the physical arrangement of CSC in a 3D space: the number of lines (nline), number of columns ( $(\mathrm{col})$, and number of boards (nboard). These variables are independent. The CSC technology chosen for this work is limited to nline $=5, n c o l=5$, and nboard $=2$. Still, this makes $5 \times 5 \times 2=50$ possible architectures. Ideally, nline, ncol, and nboard should be studied independently, but the Printed Circuit Boards (PCB) manufacturing process is cheaper when done in quantity. The cost of the experiment is reduced when identical boards with a given $n c o l$ and nline are constructed and then stacked up to form a ncol $\times$ nline $\times 2$ and ncol $\times$ nline $\times 3$.

In this work, the number of columns is clamped to five in order to keep the current flowing through the power interconnections below their maximum ratings. This is especially critical for parallel associations were the current supported by the interconnection element in our technology is limited to $30 \mathrm{~A}$. So, five conversion cells in a line, connected in parallel working at $5 \mathrm{~A}$ each, would result in $25 \mathrm{~A}$, which is more than $80 \%$ of the interconnection element limit. Of course, it would remain possible to design PCAs with up to 10 columns with the CSC operating at $3 \mathrm{~A}$ max or even 30 columns with the CSC limited at $1 \mathrm{~A}$. In this work, the boundaries are set at five lines, five columns, and two boards in order to squeeze prototyping costs.

In order to define which PCAs are manufactured and implemented for testing, the number of columns and the number of lines are the only variables that are analyzed. Since both can vary from 1 to 5 , there are 25 possible choices. Among the possibilities, six have more than 14 conversion standard cells: these PCAs would amplify the complexity of the experiments because they would require a test bench equipped with larger power supplies and electronic loads. Among the 19 remaining solutions, it was decided to do a sampling that contains at least one board containing 1,2,3, 4 and 5 lines and 1, 2, 3, 4 and 5 columns. The selected boards chosen to be fabricated are ( $\mathrm{n}^{\mathrm{o}}$ of lines, $\mathrm{n}^{\mathrm{o}}$ of columns): $(1,1)$; $(5,1) ;(2,3) ;(4,2) ;(3,4) ;(1,5)$.

As two identical boards, among the selected one, can be stacked, there are 12 different architectures to be tested. Each one has one to three dimensions (as presented in Figure 1) and can be connected either in ISOP, IPOS, IPOP, or ISOS. This work profits from the natural balance mechanism that ISOP and IPOS converters present as illustrated in [25] 
and will perform tests only with these two types of connections. All PCAs that were tested are presented in Figure 8.
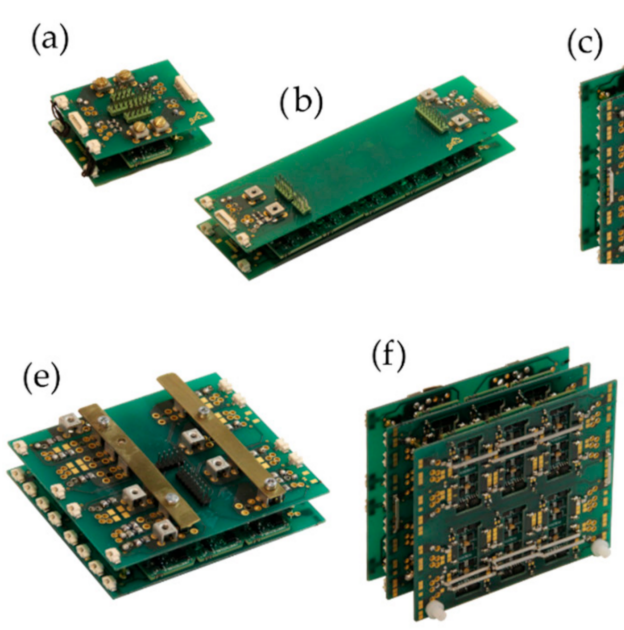

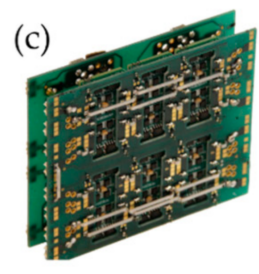

(g)

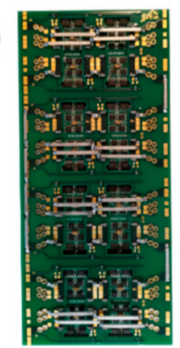

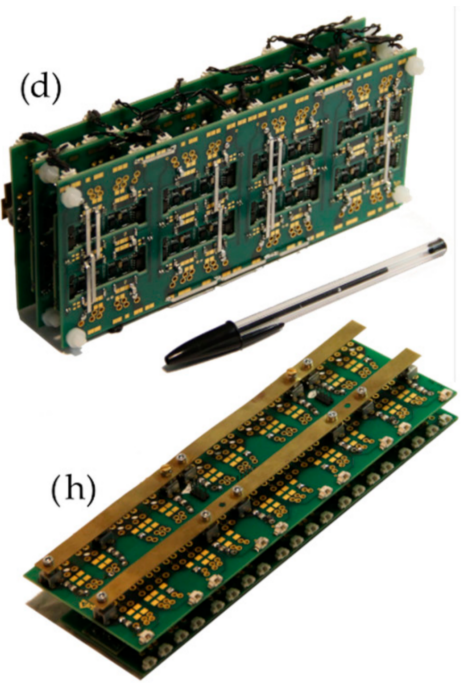

Figure 8. PCAs chosen to be tested. (a) PCA 1 line, 1 column, 1 board. (b) PCA 1 line, 5 columns, 1 board. (c) PCA 2 lines, 3 columns, 1 board. (d) PCA 4 line, 2 column, 2 boards. (e) PCA 3 lines, 4 columns, 1 board. (f) PCA 2 line, 3 column, 2 board. (g) PCA 4 lines, 2 columns, 1 board. (h) PCA 5 lines, 1 column, 1 board.

\subsection{Automated Test Bench}

Due to the high number of experiments, an automated test bench was constructed. This test bench consists of a controlled environment wind tunnel, which has fans on one side and an anemometer on the other. Right after the fans, there are heating resistors that can heat up the air, emulating ambient temperatures from room temperature up to $70{ }^{\circ} \mathrm{C}$. The interior of the wind tunnel has six temperature sensors. The device is presented in Figure 9. All data are sent to a computer where all devices can be controlled by a LabVIEW system. In addition, a power source and an electronic load are controlled in order to apply the desired voltage/current in the input and output of the PCAs. The inside shape of the tunnel can be adapted in order to present a cross-section that is identical to the one of each PCA. In such a way, the air force is channeled properly into the PCA, as it would be the case in the specific housing with dedicated fans.

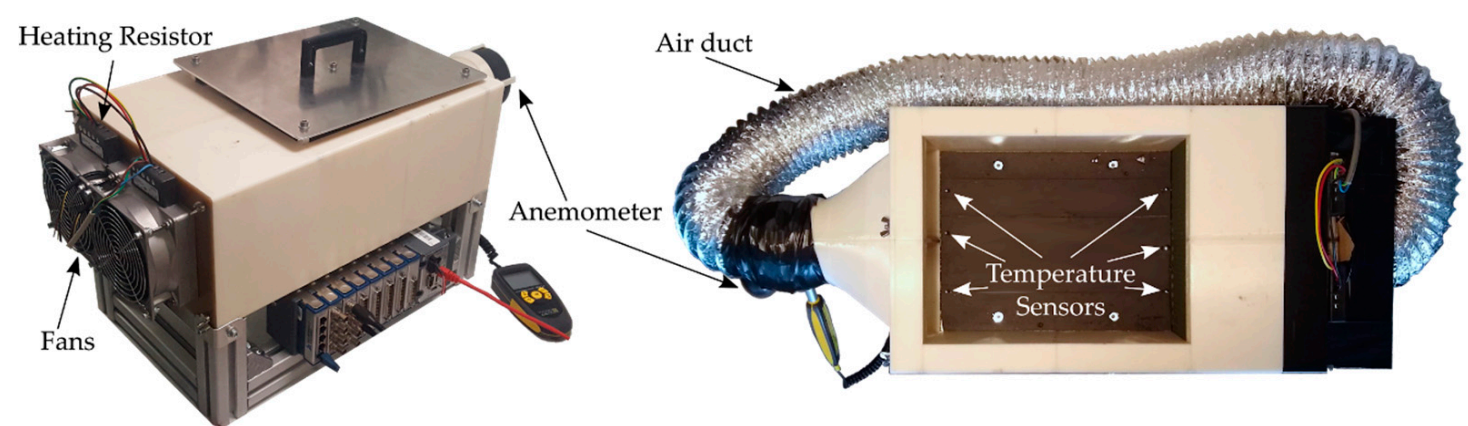

(a)

(b)

Figure 9. (a) Wind tunnel. (b) Top view of the wind tunnel with the air duct in place to recycle the warm air.

In this work, the experimental setup followed the ranges defined in the DOE to the extent of the precision of the sensors in the wind tunnel. Figure 10 presents a complete experimental characterization cycle for one PCA. In total, 360 different operating points were 
tested, and for each of them, nine measurements were repeated and averaged. The total number of measurements per variable and per characterization cycle is 3240, representing about $30 \mathrm{~h}$ of tests per PE converter.

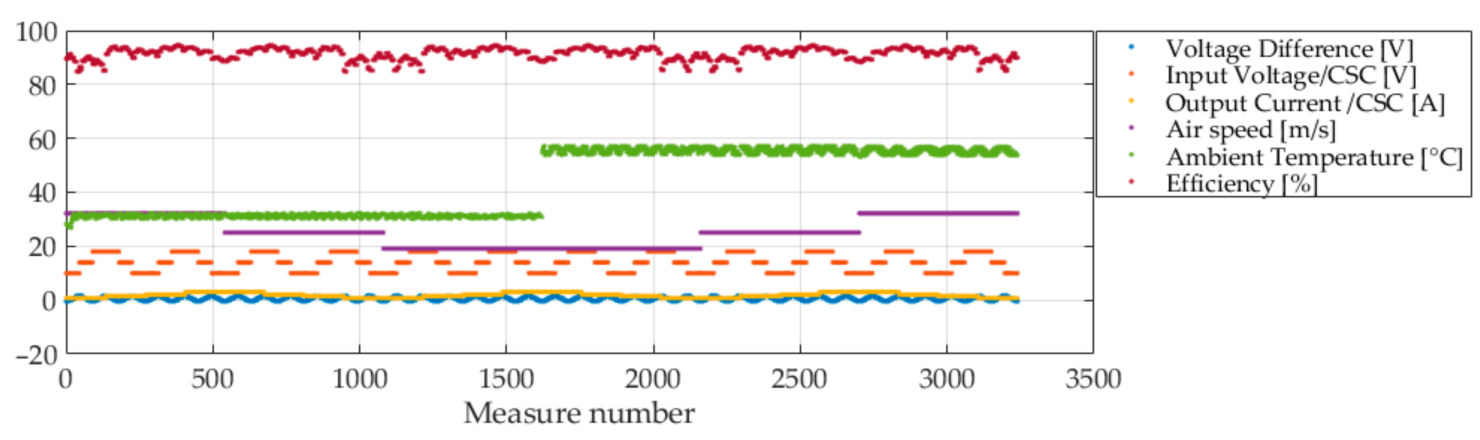

Figure 10. A complete experimental characterization cycle for one PCA.

\section{Experimental Results and Statistical Models}

After performing the experimental procedure in the eight chosen PCAs, 2548 measurement points were obtained. Each operating point was repeated nine times, resulting in a total of 22,932 measurement points. In order to reduce the equipment measurement errors, this work used the average value of the nine repetitions. The complete dataset with 2548 experiment points is displayed in Figure 11. The eleven plots present each input variable as a function of the two outputs: efficiency in the left $y$-axis and converter temperature in the right $y$-axis. The data acquired in Section 4 , in the one variable at a time test, are also added to the dataset.

Statistical modeling uses real-world variables, bundled in datasets, to train mathematical models and make predictions with a certain degree of confidence. This work aims to build/fit a model capable of predicting the efficiency and the temperature of a PCA for the 11 input variables presented in the last section. As both output variables are continuous, this is a typical regression problem.

There are many modeling techniques to build a regression model. Typically, they can be divided in parametric models and non-parametric models [26]. Parametric models can be easily used when the relation between input and output variables are already known to the user; e.g., the temperature of the converter varies linearly with the ambient temperature, or the efficiency has a $1 / x$ relation with the input voltage. However, when dealing with many input variables and some with behaviors that are hard to guess, the parametric models became prone to bias error [26].

In contrast, non-parametric models make no assumptions about which mathematical function best models the data. These models use the whole dataset as input to a noninterpretable algorithm/equation that aims to predict as close as possible the output data without being too wiggly or rough [26]. As these methods make no pre-assumption about the function shape, non-parametric fits can model a wide variety of shapes, making the modeling process much more straightforward, especially in multi-dimensional problems. However, these non-parametric methods required more data than parametric models to obtain precise predictions, and usually, it is impossible to interpret the result.

Gaussian Process Regression (GPR) is a particular type of non-parametric model. Considered sometimes as a meta-parametric technique (or semi-parametric), the GPR does not have physical parameters as parametric models, it has so-called hyper-parameters that grant the user some degree of tuning. The benefits of the GPR method are that no prior knowledge about the shape of the response is required, making it robust against the bias error as other non-parametric methods. In addition, it is still robust if only a small dataset is available for training. 


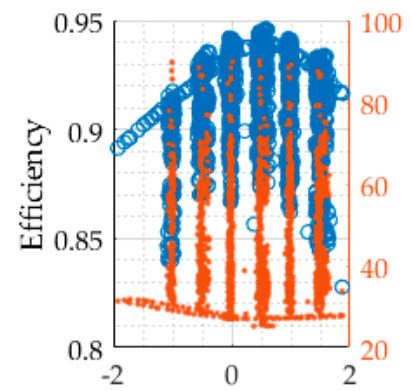

Voltage Difference (Vi-Vo) [V]
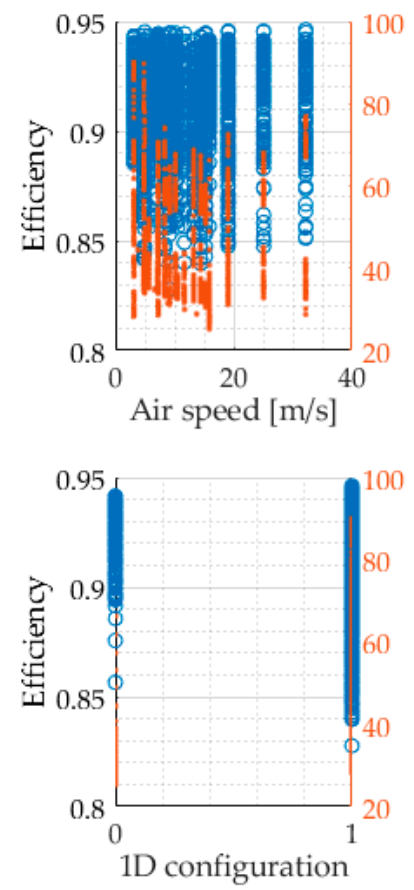

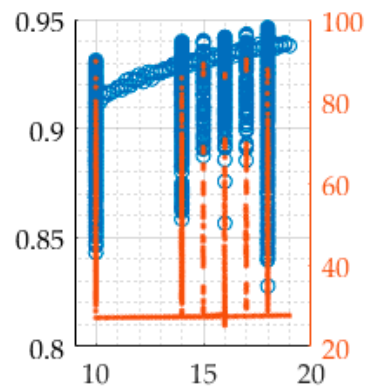

Input voltage/CSC [V]
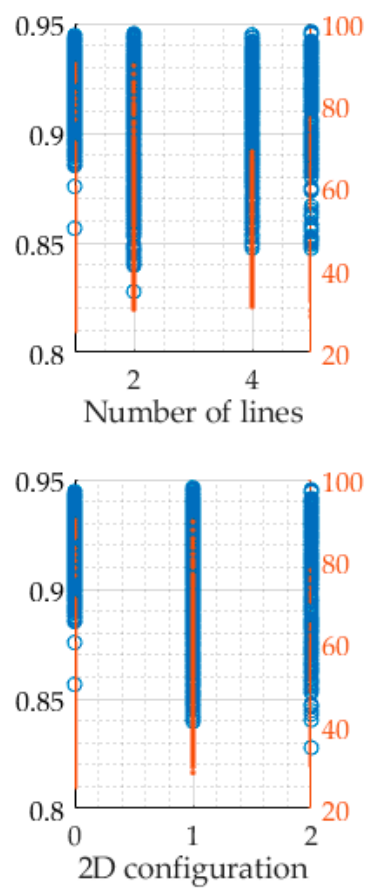

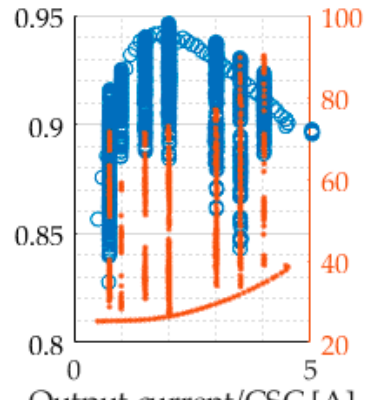

Output current/CSC [A]
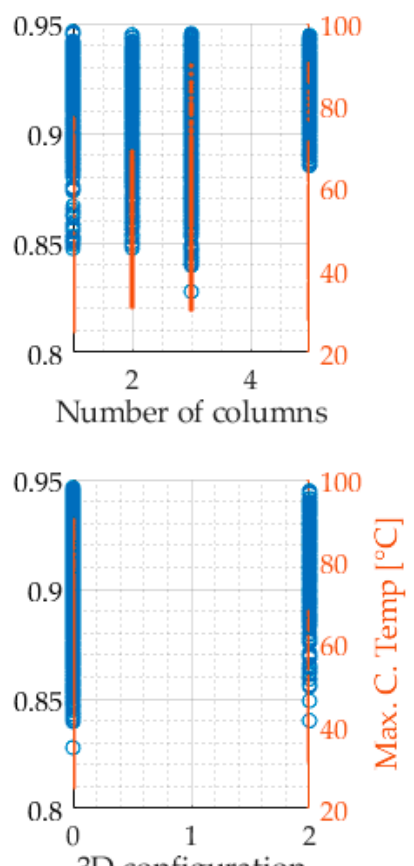

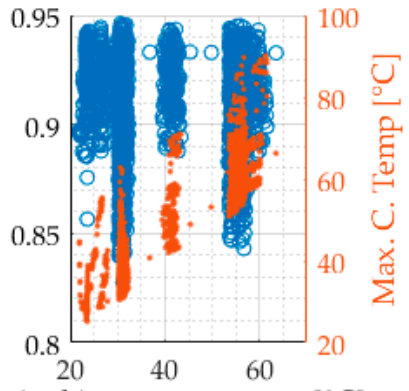

Ambient temperature $\left[{ }^{\circ} \mathrm{C}\right]$

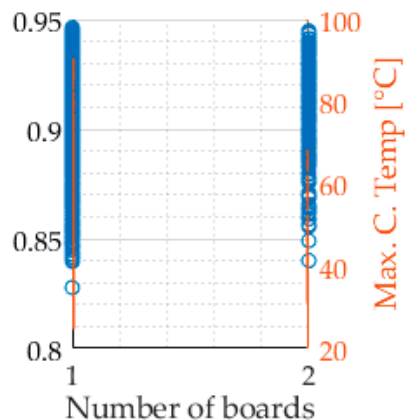

Figure 11. The complete dataset containing the 2548 experiments points. The 11 plots contain individually each input variable on the $x$-axis and the two output variables on the $y$-axis (efficiency in the left $y$-axis and the maximum converter temperature in the right $y$-axis).

This work opted to use the Gaussian Process Regression (GPR) to create the models for predicting the converter efficiency and temperature. This technique has already been applied in a few topics in the electrical engineering field such as in [27] to predict the health of batteries, in [28] to estimate the lifetime of IGBT devices, and in [29] to create models of the switching process of MOSFETs.

The GPR method create a model that mathematically assures a minimal error of the prediction if the appropriate kernel and its associated meta-parameters are used. For the sake of brevity, mathematical details on GPR are not presented in this work; the reader is invited to read more in [27-30]. In order to fit a model using the GPR method, it is required to find which kernel best suits the problem under study [30]. This work opted for exploring four classic GPR kernels suited for non-linear systems: exponential (EX), Matern 5/2 (M52), rational quadratic $(\mathrm{RQ})$, and squared exponential (SE). The $k$-fold cross-validation was used to fit (with $\mathrm{k}=5)$. Their root means square error (RMSE) and training time are presented in Table 4.

The value of the RMSE displayed in Table 2 represents the training error of the models, or how close the predictions are to the estimated results used through the training process. These values do not necessarily demonstrate how good the predictions are but instead indicate how close these are to the training data overall. The data used to train the model can 
be used to carry out some initial analysis of the accuracy of its results. Still, the validation of the model must be done with an independent set of data.

Table 4. The root mean square error and training time of each model and its correspondent kernel both for the efficiency and temperature.

\begin{tabular}{ccccc}
\hline & \multicolumn{2}{c}{ Efficiency Models } & \multicolumn{2}{c}{ Temperature Models } \\
\hline \multirow{2}{*}{ Kernel } & $\begin{array}{c}\text { RMSE } \\
\text { [Points of Efficiency } \mathbf{~ 1 0 ~}^{-3} \text { ] }\end{array}$ & $\begin{array}{c}\text { Training Time } \\
{[\mathbf{m i n}]}\end{array}$ & $\begin{array}{c}\text { RMSE } \\
{\left[{ }^{\circ} \mathbf{C}\right]}\end{array}$ & $\begin{array}{c}\text { Training Time } \\
{[\mathbf{m i n}]}\end{array}$ \\
\hline Exponential (EX) & 2.85 & 28.9 & 2.22 & 7.6 \\
Matern 5/2 (M52) & 1.27 & 23.9 & 16.34 & 5.2 \\
Rational Quadratic (RQ) & 1.34 & 22.1 & 7.46 & 12.4 \\
Squared Exponential (SE) & 1.43 & 12.9 & 5.96 & 4.7 \\
\hline
\end{tabular}

A primary evaluation of the quality of the prediction of each kernel can be made by comparison between the predictions and some well-known physical characteristics of a power converter. To perform this comparison, Figure 12 presents the models predictions of the efficiency of a PCA (two lines, three columns, two boards) as a function of its output current. All operating point variables, despite output current, are kept constant, and their values are displayed in the box inside each respective plot. The gray dots represent the $95 \%$ confidence region of the prediction, while the blue dots show the actual predicted values.
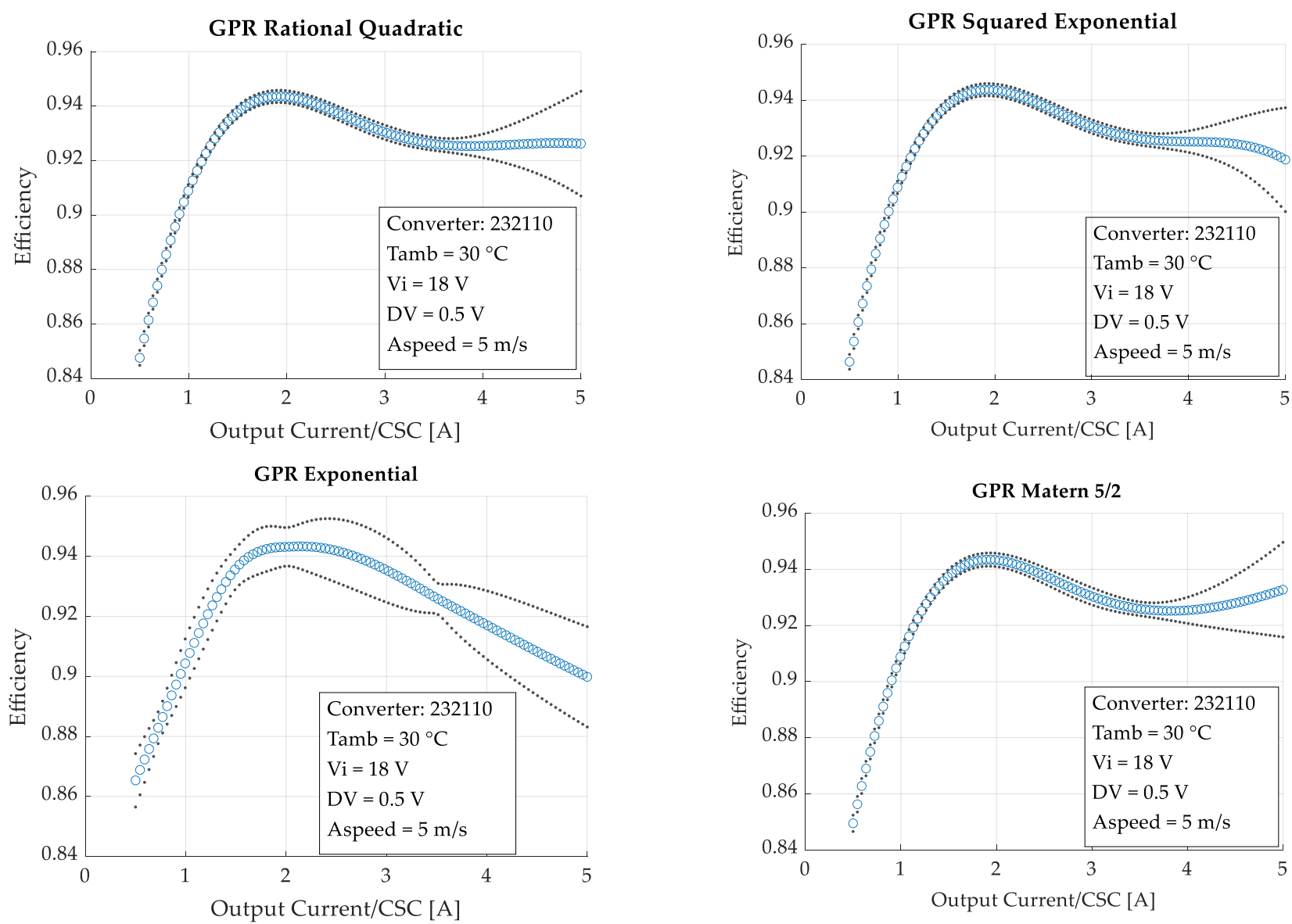

Figure 12. Predictions of the efficiency versus the output current with the 11 input variables assuming values close to the points presented in the dataset. Blue circles: predicted values. Gray dots: 95\% confidence interval. The PCA code 232,110 stands for two lines, three columns, one board, 1D: Conversion-Standard Cells (CSCs) in each line configured in input parallel output series (IPOS), 2D: columns of CSCs configured in IPOS, 3D: No connection. 
It can be seen in Figure 12 that the models trained with kernels M52, the RQ, and the SE present high accuracy until $3.5 \mathrm{~A}$, which is the region in which most of the training data is concentrated. Past this current, these kernels have physically incoherent results. Only the EX kernel presents physically coherent results after 3.5 A; however, it has a higher incertitude than the other three kernels in predictions with lower currents. Depending on the predicted point, one kernel or another can be used for best results.

In order to evaluate the model interpolation capability, this work used a new and independent dataset. A new PCA has been fabricated and tested for this purpose. This new PCA has an architecture of three lines, four columns, and one board, and a configuration of 1D: IPOS, 2D: IPOS, 3D: NC. It performed an experimental campaign of 1240 measures in 139 different operating points with nine repetitions for each point. To test the performance of the kernels, the exact same values of operating points applied to the converter during its empirical tests are used as input data in the models. Their predictions are compared with the real efficiency measured during the experiment. The errors that each model presented are presented in Figure 13. The $y$-axis units are points of efficiency; e.g., at a given operating point where the efficiency was 0.925 and the prediction was 0.935 , the efficiency error equals 0.01 .
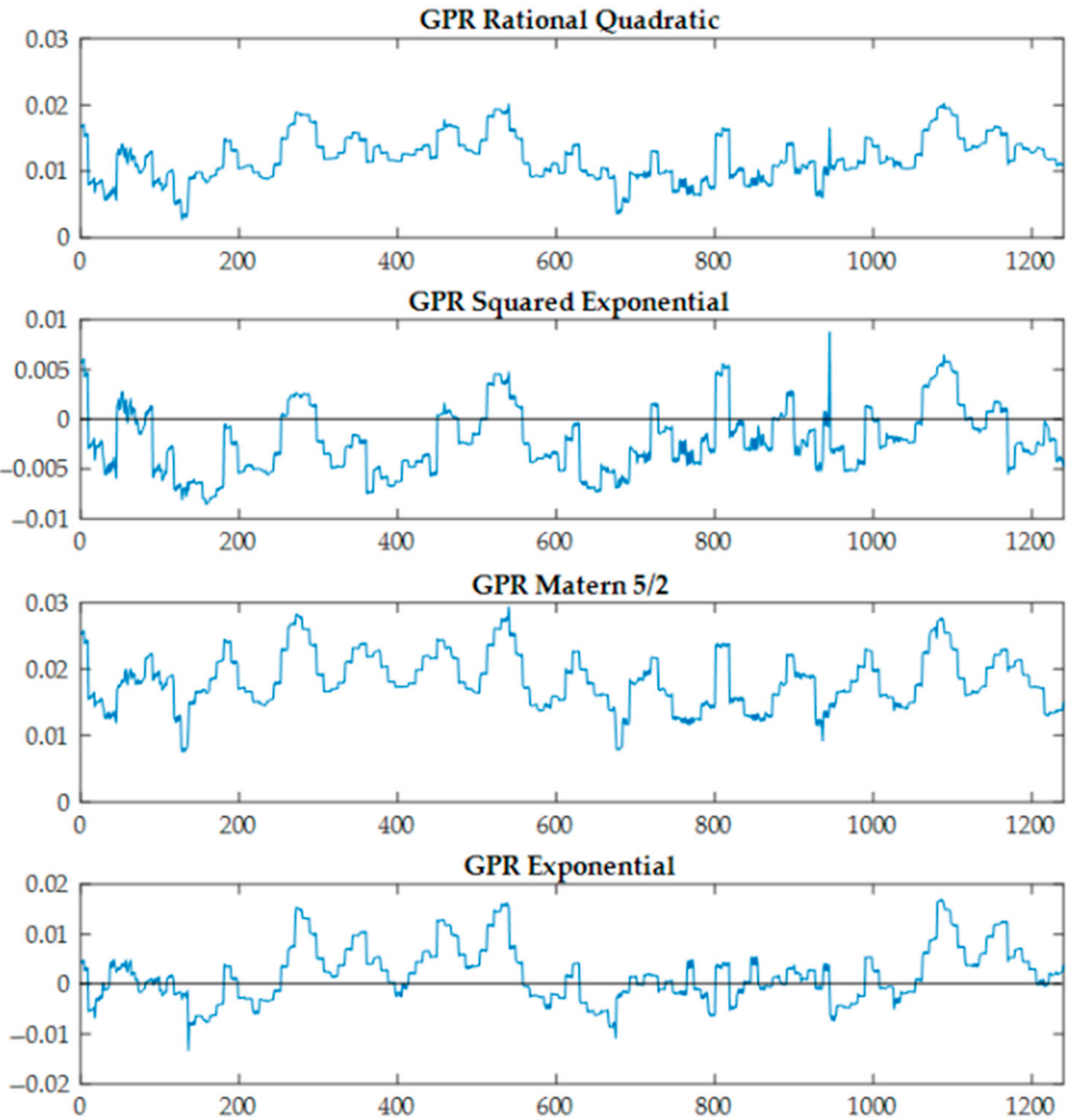

Figure 13. The efficiency error (predicted efficiency value-real efficiency value) that each model presents for the 1240 experimental measurements performed with the prototype 431110.

As presented in Figure 13, the SE kernel shows an outstanding performance, predicting all 139 operating points with less than 0.01 point of efficiency $(1 \%)$ from the actual experimental measures. The EX also presents a decent accuracy. However, the M52 and RQ kernels overvalue the efficiency in all predictions. 
The same comparison was performed with the GPR model focused on predicting the operating temperature of the PCA as a function of all 11 input variables. The same four kernels used for the efficiency model were used to train the temperature GPR model. Similarly, the same independent dataset from the new PCA was used for the final validation. The errors of the temperature predicted by the model to the actual temperatures of the PCA are presented in Figure 14.
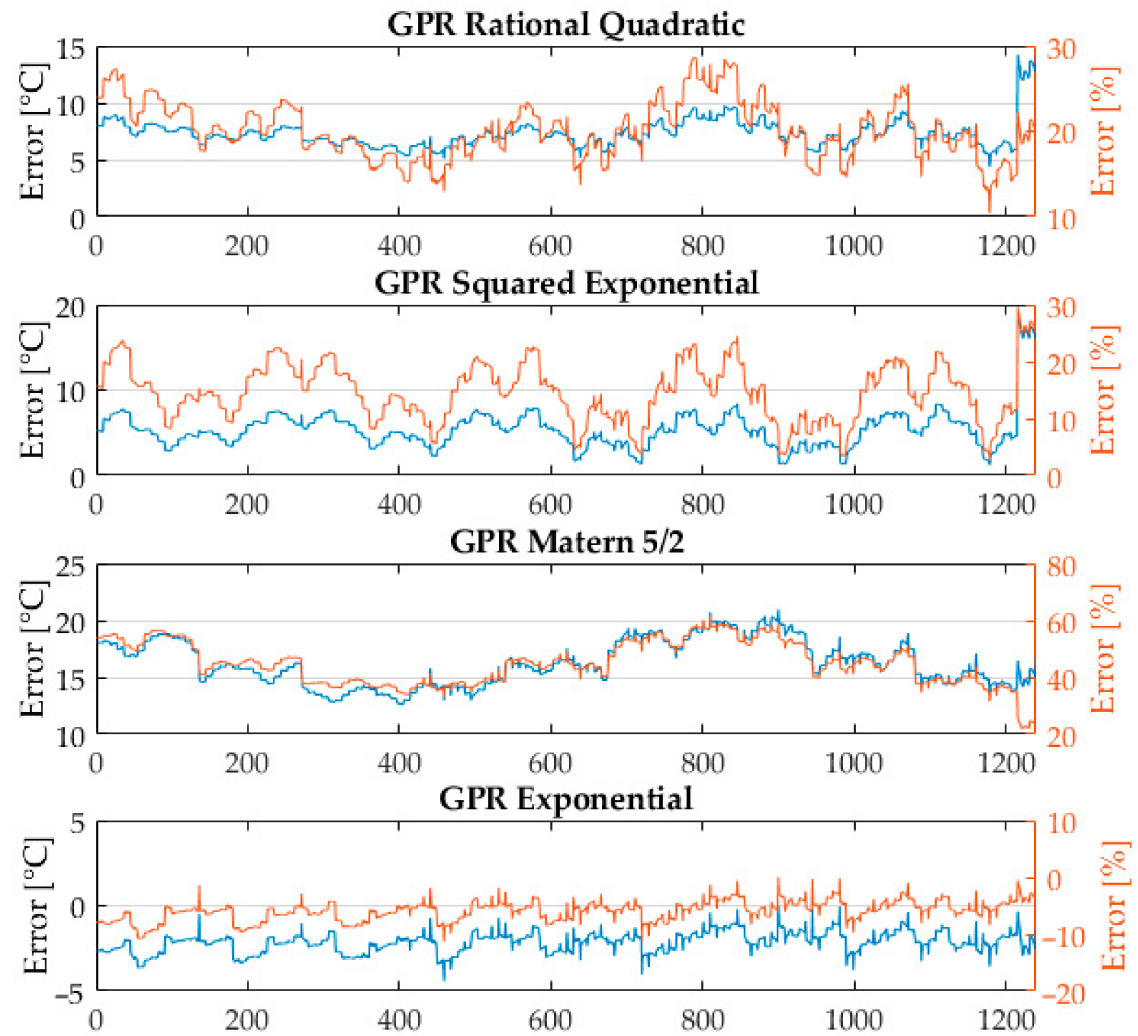

Figure 14. The converter temperature error (predicted efficiency value-real efficiency value) for each model.

The next section shows how virtual prototyping can be carried out based on these models and their accuracy. A brief discussion on the limits of the model and their needs in terms of data is also proposed.

\section{Virtual Prototyping and ADFM Discussion}

In order to demonstrate how the PCA concept works, this section presents a practical example of the design process of a converter. The specifications of the converter are presented in Table 5. Its specifications correspond to those of a DC-DC isolated converter for charging and discharging a $\mathrm{LiFePO}_{4} 36 \mathrm{~V}$ battery stack from a $120 \mathrm{~V} \mathrm{DC}$ bus.

Table 5. Specifications of a DC-DC converter for a battery charging application.

\begin{tabular}{cc}
\hline Variable & Value \\
\hline Input Voltage (Battery Side) & $32 \mathrm{~V}$ to $40 \mathrm{~V}$ \\
Output Current & $8 \mathrm{ADC} \max$ \\
Isolation & $1.5 \mathrm{kV}$ \\
Maximum Dimensions (Width $\times$ Length $\times$ Height) & $10 \mathrm{~cm} \times 30 \mathrm{~cm} \times 10 \mathrm{~cm}$ \\
Minimum Efficiency at Nominal Power & $91 \%$ \\
Maximum Weight & $1 \mathrm{~kg}$ \\
\hline
\end{tabular}


Using the specifications presented in Table 5 as input into the ADFM algorithm, the algorithm then selects the technology platform, which is the most adequate to fulfill the required specifications. During this work, the only TP available was the one presented in Section 2. Then, the algorithm performs calculations to define how many CSCs are required and in which configuration they must be in order to fulfill the required specifications. For the sake of brevity, this work does not present details on the algorithm calculations. However, its main mechanism is to find out how many CSCs must be connected in series to achieve the desired voltage and in parallel to achieve the desired current. All possible solutions found by the algorithm are presented in Table 6 .

Table 6. List of PCAs that are able to perform the power conversion described in Table 3.

\begin{tabular}{|c|c|c|c|c|c|c|c|c|c|c|c|c|}
\hline No. & Architecture & $\begin{array}{l}\text { No. of } \\
\text { CSCs }\end{array}$ & Configuration & $\begin{array}{c}\text { Max } \\
\text { Power }[W]\end{array}$ & $\begin{array}{l}\text { Max Input } \\
\text { Voltage [V] }\end{array}$ & $\begin{array}{c}\text { Max Output } \\
\text { Voltage [V] }\end{array}$ & $\begin{array}{l}\text { Max Output } \\
\text { Current [A] }\end{array}$ & $\begin{array}{c}\text { CPR } \\
{[\%]}\end{array}$ & $\begin{array}{l}\text { Length } \\
{[\mathrm{mm}]}\end{array}$ & $\begin{array}{l}\text { Width } \\
\text { [mm] }\end{array}$ & $\begin{array}{c}\text { Height } \\
{[\mathrm{mm}]}\end{array}$ & $\begin{array}{c}\text { Weight } \\
\text { [mm] }\end{array}$ \\
\hline 1 & $2 \times 6 \times 1$ & 12 & PS-SP-0 & 1200 & 40 & 120 & 10 & 100 & 94 & 144 & 13 & 420 \\
\hline 2 & $1 \times 6 \times 2$ & 12 & PS-0-SP & 1200 & 40 & 120 & 10 & 100 & 47 & 144 & 26 & 420 \\
\hline 3 & $2 \times 3 \times 2$ & 12 & PS-PS-SP & 1200 & 40 & 120 & 10 & 100 & 94 & 72 & 26 & 480 \\
\hline 4 & $2 \times 3 \times 2$ & 12 & SP-PS-PS & 1200 & 40 & 120 & 10 & 100 & 94 & 72 & 26 & 480 \\
\hline 5 & $2 \times 7 \times 1$ & 14 & PS-SP-0 & 1400 & 40 & 140 & 10 & 85.7 & 94 & 168 & 13 & 480 \\
\hline 6 & $1 \times 7 \times 2$ & 14 & PS-0-SP & 1400 & 40 & 140 & 10 & 85.7 & 47 & 168 & 26 & 480 \\
\hline 7 & $2 \times 4 \times 2$ & 16 & PS-PS-SP & 1600 & 40 & 160 & 10 & 75 & 94 & 96 & 26 & 600 \\
\hline 8 & $4 \times 2 \times 2$ & 16 & SP-PS-PS & 1600 & 40 & 160 & 10 & 75 & 188 & 48 & 26 & 720 \\
\hline
\end{tabular}

The architectures in which the CSCs are placed are presented in Table 4 with the code (number of lines $\times$ number of columns $\times$ number of boards). The configuration indicates the type of connections in which the CSCs are connected (SP for input series output parallel and PS for input parallel output series). In some solutions, the input and output voltage maximum values are higher than the required specifications, but they are able to work at the desired voltage. The table also presents the CSC Power Ratio (CPR), which represents the ratio (nominal power/max power) in which the CSCs will work.

Based on the models developed in Section 5, the performance of all the solutions presented in Table 4 can be compared in detail. The efficiency of each PCA is presented in Figure 15. The plots present the charging and discharging process of the battery for a constant DC bus voltage of $120 \mathrm{~V}$. When charging the battery, the PCA operates in buck mode (from $120 \mathrm{~V}$ to $36 \mathrm{~V}$ ), and while discharging the PCA, it operates in boost mode (from $36 \mathrm{~V}$ to $120 \mathrm{~V}$ ). As the CSCs are DAB converters, it is expected that they present different efficiency values when working in buck or in boost modes. It is imperative to highlight that the ADFM method presents these results automatically without any time-based simulations.

Virtual prototyping can be used to perform a complete analysis of the performance of each PCA for multiple operation points or even a mission profile. Figure 15 shows the mission profile set to charge a specific type of battery. The battery cells studied in the example are the model LIR18650 from the company EEMB [31]. It is possible to identify in the battery datasheet the charge and discharge profiles. These data are used to set up the mission profiles for the charge and the discharge sequences. The battery pack is made of five parallel connected groups of nine cells connected in series. Its charge and discharge characteristic are shown in Figure 16.

The models created in Section 5 can also be used to predict the performance that each PCA has at each operating point (voltage and current) for an entire mission profile comprising $180 \mathrm{~min}$ of the charging sequence and $60 \mathrm{~min}$ of the discharging sequence. The three most efficient PCAs presented in Figure 15 were considered for comparison: 322211, 271120, and 422112. Figure 17 shows the instantaneous power loss that each of these solutions presents during the charge and discharge cycles. 

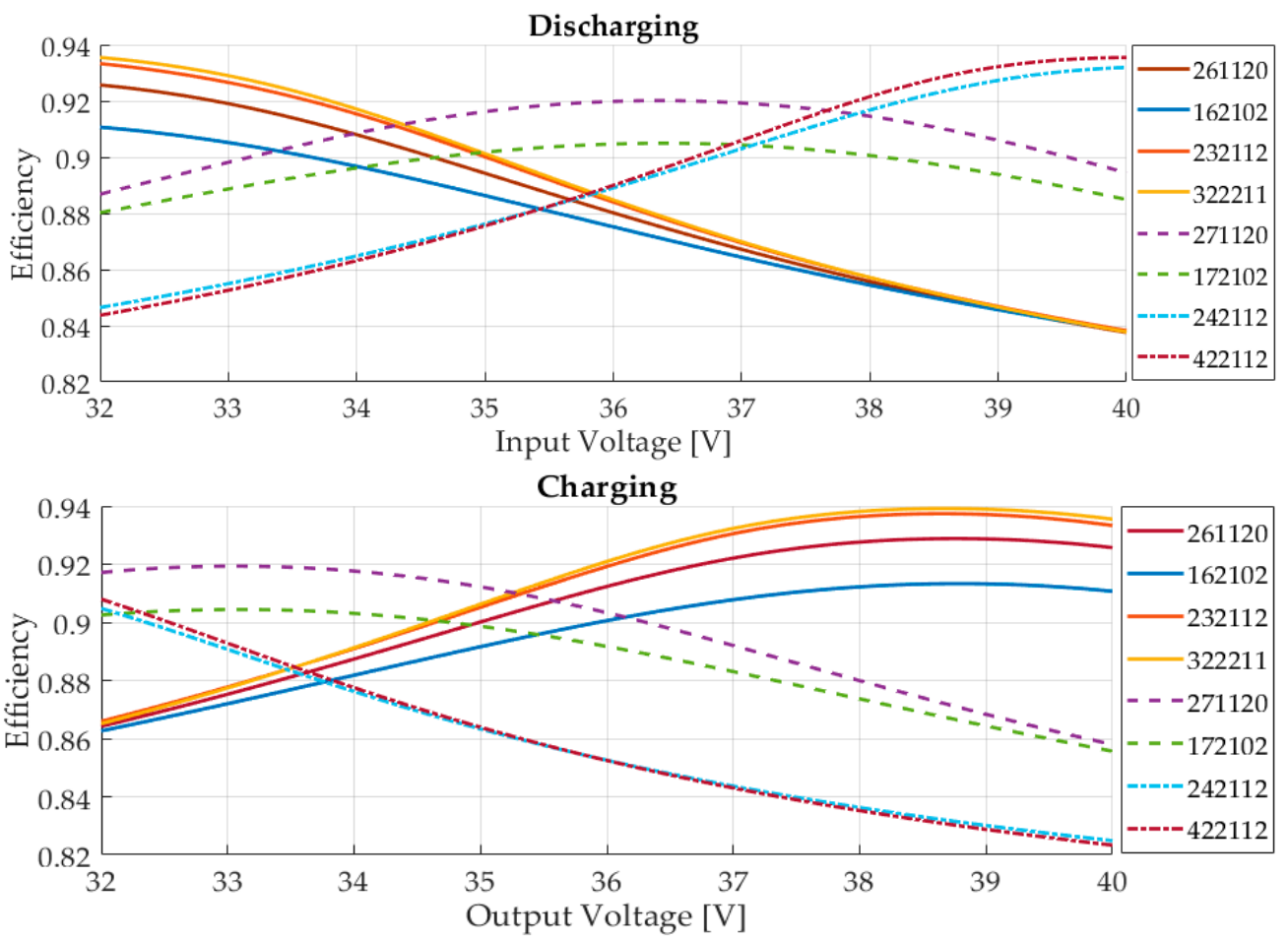

Figure 15. Efficiency versus the input voltage (charging sequence) and output voltage (discharging sequence) for all solutions presented in Table 4 . The other input variables are fixed: Air speed $=5 \mathrm{~m} / \mathrm{s}$; Ambient temperature $=30^{\circ} \mathrm{C}$. In charging mode: Input voltage $=120 \mathrm{~V}$, Input current $=6 \mathrm{~A}$. In discharging mode: Output voltage $=120 \mathrm{~V}$ Output current $=6 \mathrm{~A}$.
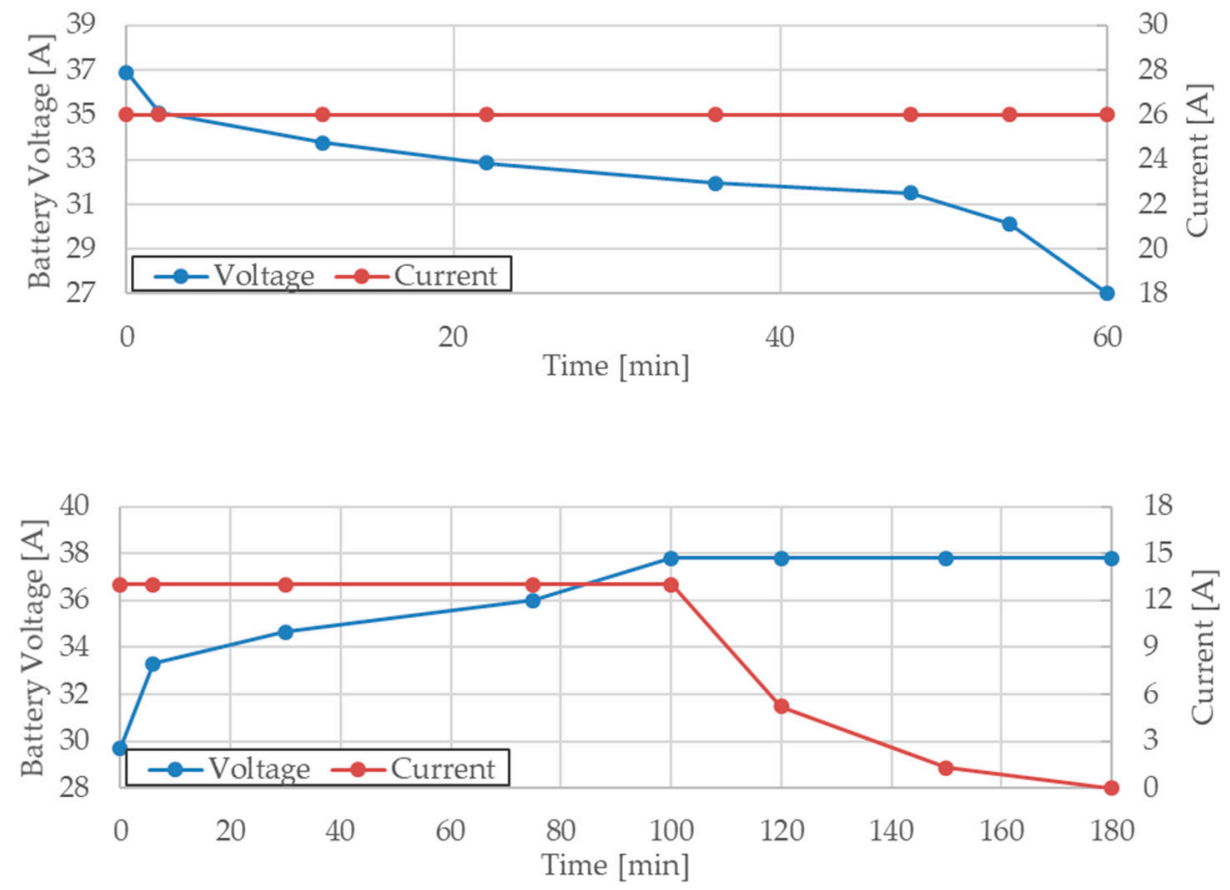

Figure 16. Mission profile of charging and discharging cycles of a battery pack containing 45 LIR18650 cells. The pack consists of five parallel connected groups of nine cells connected in series. 

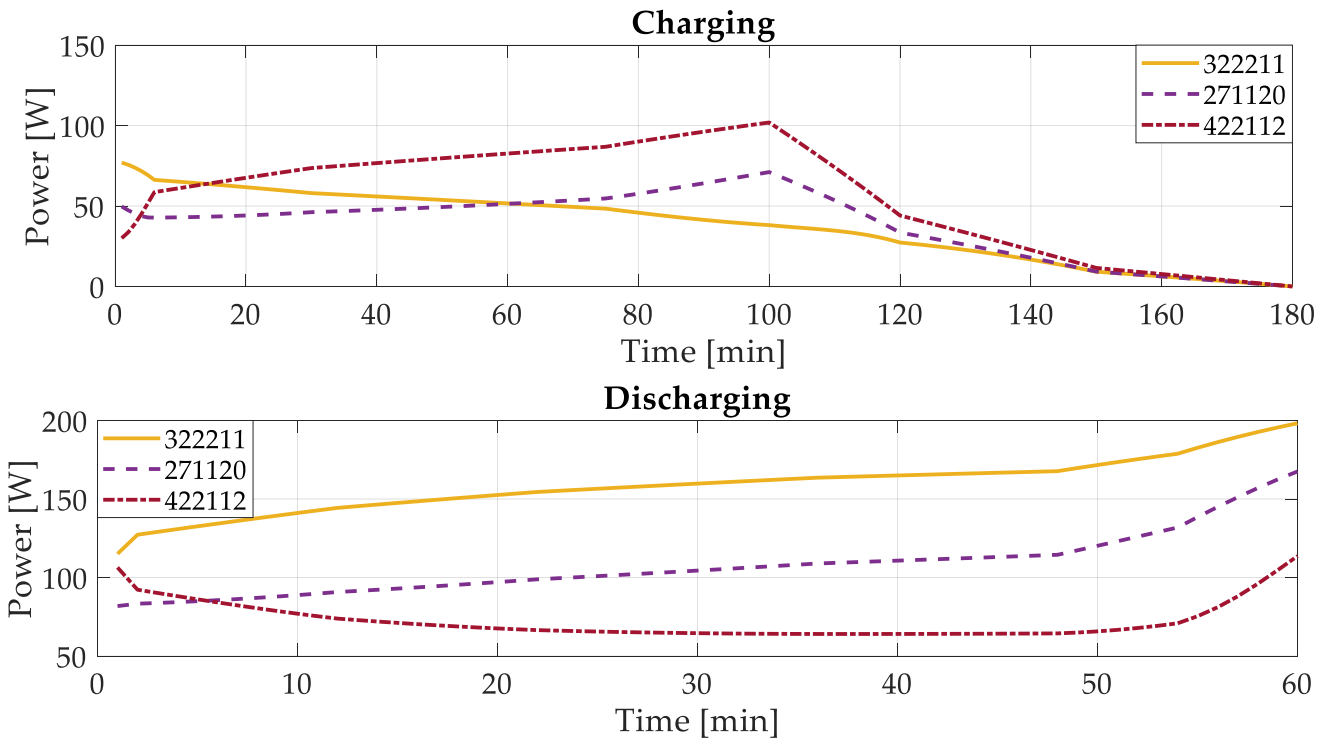

Figure 17. The instantaneous power losses that each PCA dissipates during the $180 \mathrm{~min}$ of charging and the $60 \mathrm{~min}$ of discharge.

The total energy dissipated during the charging and discharging cycles of each PCA can be calculated by integrating the instantaneous power losses. Figure 18 presents results for each PCA during charge, discharge, and the whole mission profile. The table includes the predictions made using the upper and lower boundaries of the 95\% (indicated by U95\% and $\mathrm{L} 95 \%$ ).

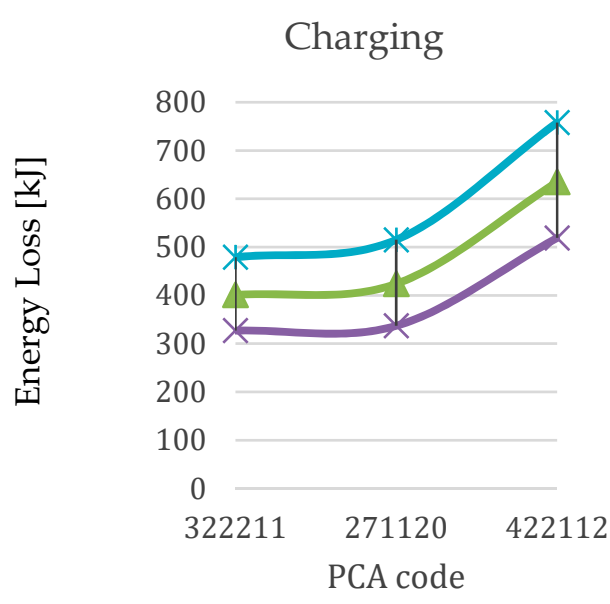

Discharging

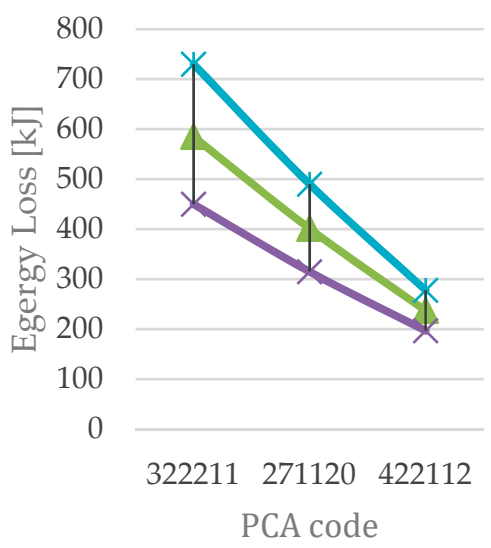

Total

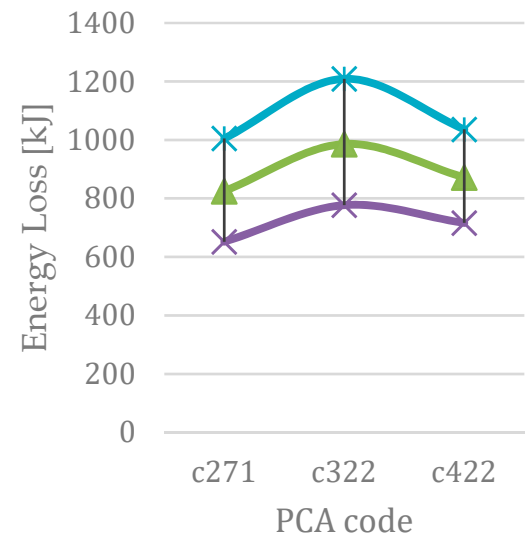

$\longrightarrow$ Prediction $\longleftarrow$ U95\% $\leftarrow$ L95\%

Figure 18. Energy loss prediction for each PCA and the upper and lower $95 \%$ confidence interval predictions.

It is possible to estimate which PCA presents the best performance for charging and discharging cycles. Figure 18 shows the predicted energy losses for each PCA for charge, discharge, and the total mission profile. It can be seen that the PCA 271120, which presents an average performance in charging and discharging, ends up being the best option for the whole mission profile.

The confidence intervals in Figure 18 show the level of precision of the proposed virtual prototype. By taking them into account, it is much less clear which prototype is should be chosen. This means that more data is required, which is mainly due to the fact that many operation points used in this virtual prototyping are actual extrapolations based on the dataset. For example, the voltage difference (DV) in the dataset is mainly concentrated in -1 to $+1.5 \mathrm{~V}$, while in the battery predictions, the DV varied from -5 to $4 \mathrm{~V}$. 
If the dataset had a wider range of DV, output current, input voltage, etc., the predictions would have been more accurate.

\section{Conclusions}

Automatic Design for Manufacturing (ADFM) in power electronics revisits the idea of what a power converter is and how to create one. A power converter is created from the interconnection of arrays of Conversion-Standard Cells (CSC), thus creating a Power Converter Array (PCA). CSCs, together with other standard cells, constitute a technology platform (TP). A designer using the ADFM method goes from a set of specifications to the manufacturing files of the PCA through a complete automated process. This process includes virtual prototyping and cross comparing of several PCAs performances. The work was divided in five sections.

Section 2 described what a technology platform is and how it is a fundamental concept in the ADFM methodology. The section also presented the concepts of architecture and configuration, and how Standard Cells are assembled to create Power Converter Arrays.

Section 3 presented a brief comparison of the traditional design flow of power converters with the ADFM methodology. It also described that one fundamental idea behind the ADFM is the use of statistical models to predict the performance of any PCA built from a given technology platform. The creation of these models was explained in the two following sections.

As several electrical and thermal parameters must be studied with several PCAs, strategies of design of experiments (DOE) were applied in order to reduce the amount of experiments. Section 4 presented the main ideas behind selecting the minimal quantity of experiments in order to get the maximum amount of information. In practice, this meant choosing which prototypes to build, in order to save resources, and under which conditions input and output variables should be measured, to save time and resources. Several details of the experimental test bench were also presented.

Section 5 discussed statistical modeling techniques, and it selected the Gaussian Process Regression (GPR) to create a model to predict the efficiency and the temperature of PCAs. The section presented a comparison between four kernels, and their performances were tested. Finally, the best kernel for predicting the efficiency and temperature was the squared exponential.

Finally, the last section presented a virtual prototyping application that compares the performance of PCAs in a charge/discharge battery application. The use of this prediction models opens up a field of exploration into the design of PCAs. Since every operating point of any PCA built with a TP that has been previously characterized can be predicted, any user can analyze the performance of PCAs under any mission profile. This opens up a field to explore optimal solutions to very unique converter specifications and might inspire advances in the field of automated design in power electronics.

The ADFM is an alternative approach to achieve a more automatic design process of power electronic converters. Interesting results were presented in this work; however, there are still many issues about this method to be investigated, such as the following:

Cost: How does the price of a PCA compare to a converter designed by a traditional method? What scale of the mass manufacture of CSCs could represent a significant price reduction for PCAs?

Reliability: A PCA contains several times more components than traditional converters. However, thanks to the multicell approach, it is possible to isolate defective cells and increase the overall reliability. There are several techniques of control and monitoring that can be applied to the methodology. In addition, since fewer types of components as well as assembly and implementation technologies are involved in the manufacture process, these could be optimized toward a very high reliability level at the CSC level, allowing the creation of very reliable PCAs. 
EMI and thermal management: Thanks to the usage of standardized elements, it might be possible to predict conducted and radiated emissions of PCAs as well as optimized thermal management conditions. In this case, the automatic design of filters and thermal needs could be achieved.

The overall approach is opening a new design and manufacturing paradigm in power electronics where the standardization of conversion blocs could shift the entire field into automated converter synthesis, with PCA converter mass production players operating various technology platforms (TP) on one side and design houses that are fabless on the other side, answering to end users' needs. Both would be linked by TP design kits, offering a full description of CSC characteristics, design, and implementation rules. Specific design tools could be developed in order to load specifications, with a comprehensive description language. Then, the design environment would be able to synthesis a PCA from the data made available in the design kits from the PCA manufacturer. This projection is very similar to what has been done, a long time ago, in digital design, and more research of ours will follow.

Author Contributions: Conceptualization, A.A., L.F.L.V., J.C.C. and Y.L.; methodology, A.A., L.F.L.V., J.C.C. and Y.L.; formal analysis, A.A., L.F.L.V., J.C.C. and Y.L.; data curation, A.A.; writing-original draft preparation, A.A.; writing-review and editing, A.A., L.F.L.V., J.C.C. and Y.L.; supervision, L.F.L.V., J.C.C. and Y.L.; project administration, J.C.C. and Y.L.; funding acquisition, J.C.C. and Y.L. All authors have read and agreed to the published version of the manuscript.

Funding: This research was funded by the Region Rhône Alpes Auvergne for its funding through project Mamaatec, Convention FEDER NRA0020041.

Conflicts of Interest: The authors declare no conflict of interest.

\section{References}

1. Marques Cardoso, A.J. Power Electronics Design Methods and Automation in the Digital Era: Evolution of Design Automation Tools. IEEE Power Electron. Mag. 2020, 7, 36-40. [CrossRef]

2. Bindra, A.; Mantooth, A. Modern Tool Limitations in Design Automation: Advancing Automation in Design Tools is Gathering Momentum. IEEE Power Electron. Mag. 2019, 6, 28-33. [CrossRef]

3. Voldoire, A.; Schanen, J.-L.; Ferrieux, J.-P.; Derbey, A.; Gautier, C. Three-Phase PWM Voltage-Source-Inverter Weight Optimization for Aircraft Application Using Deterministic Algorithm. Electronics 2020, 9, 1393. [CrossRef]

4. POWERFORGE-Power Design Technologies SA. Available online: https://powerdesign.tech/powerforge/ (accessed on 8 December 2020).

5. $\quad$ Evans, T.M.; Le, Q.; Mukherjee, S.; Al Razi, I.; Vrotsos, T.; Peng, Y.; Mantooth, H.A. PowerSynth: A Power Module Layout Generation Tool. IEEE Trans. Power Electron. 2019, 24, 5063-5078. [CrossRef]

6. Ericsen, T.; Tucker, A. Power Electronics Building Blocks and potential power modulator applications. In Proceedings of the Conference Record of the Twenty-Third International Power Modulator Symposium (Cat. No. 98CH36133), Rancho Mirage, CA, USA, 25 June 1998; pp. 12-15.

7. Ericsen, T. Power Electronic Building Blocks-a systematic approach to power electronics. In Proceedings of the 2000 Power Engineering Society Summer Meeting (Cat. No.00CH37134), Seattle, WA, USA, 16-20 July 2000; Volume 2, pp. 1216-1218.

8. Lee, F.C. Power electronics building block and system integration. In Proceedings of the IPEMC 2000, Third International Power Electronics and Motion Control Conference (IEEE Cat. No.00EX435), Beijing, China, 15-18 August 2000; Volume 1, pp. 1-8.

9. Wang, F.; Rosado, S.; Thacker, T.; Boroyevich, D. Power electronics building blocks for utility power system applications. Power Electron. In Proceedings of the 4th International Power Electronics and Motion Control Conference, Xi'an, China, 14-16 August 2004; Volume 1, pp. 354-359.

10. Mariut, F.; Rosu, S.; Tenconi, R.B.A. Multiphase modular power converter using the PEBB concept and FPGA-based direct high speed voltage measurement. In Proceedings of the 2015 17th European Conference on Power Electronics and Applications (EPE'15 ECCE-Europe), Geneva, Switzerland, 8-10 September 2015; pp. 1-10.

11. Iyer, A.R.; Kandula, R.P.; Moghe, R.; Hernandez, J.E.; Lambert, F.C.; Divan, D. Validation of the Plug-and-Play AC/AC Power Electronics Building Block (AC-PEBB) for Medium-Voltage Grid Control Applications. IEEE Trans. Ind. Appl. 2014, 50, $3549-3557$. [CrossRef]

12. Wang, F.; Zhang, Z.; Ericsen, T.; Raju, R.; Burgos, R.; Boroyevich, D. Advances in Power Conversion and Drives for Shipboard Systems. Proc. IEEE 2015, 103, 2285-2311. [CrossRef]

13. Ortmann, M.S.; Hoffmann, W.; Mussa, S.A.; Heldwein, M.L. Multilevel multistate switching cells PEBBs as the basis for the implementation of advanced rectifiers. In Proceedings of the 2013 Twenty-Eighth Annual IEEE Applied Power Electronics Conference and Exposition (APEC), Long Beach, CA, USA, 17-21 March 2013; pp. 1871-1877. 
14. Boroyevich, D. Building block integration in power electronics. In Proceedings of the 2010 IEEE International Symposium on Industrial Electronics, Bari, Italy, 4-7 July 2010; pp. 3673-3678.

15. Boroyevich, D.; Lee, F.C.; van Wyk, J.D.; Lu, G.Q.; Scott, E.P.; Xu, M.; Burgos, R.; Wang, F.; Jahns, T.M.; Lipo, T.A.; et al. IPEM-based power electronics system integration. In Proceedings of the 5th International Conference on Integrated Power Electronics Systems, Nuremberg, Germany, 11-13 March 2008; pp. 1-10.

16. Chen, R.; Canales, F.; Yang, B.; van Wyk, J.D. Volumetric Optimal Design of Passive Integrated Power Electronics Module (IPEM) for Distributed Power System (DPS) Front-End DC/DC Converter. IEEE Trans. Ind. Appl. 2005, 41, 9-17. [CrossRef]

17. Meynard, T.A.; Foch, H. Multi-level conversion: High voltage choppers and voltage-source inverters. In Proceedings of the PESC '92 Record. 23rd Annual IEEE Power Electronics Specialists Conference, Toledo, Spain, 29 June-3 July 1992; Volume 1, pp. 397-403.

18. Gateau, G.; Maussion, P.; Meynard, T. Fuzzy phase control of series multicell converters. In Proceedings of the 6th International Fuzzy Systems Conference, Barcelona, Spain, 5 July 1997; Volume 3, pp. 1627-1633.

19. TMeynard, A.; Foch, H.; Thomas, P.; Courault, J.; Jakob, R.; Nahrstaedt, M. Multicell converters: Basic concepts and industry applications. IEEE Trans. Ind. Electron. 2002, 49, 955-964. [CrossRef]

20. Ertl, H.; Kolar, J.W.; Zach, F.C. A novel multicell DC-AC converter for applications in renewable energy systems. IEEE Trans. Ind. Electron. 2002, 49, 1048-1057. [CrossRef]

21. Kasper, M.; Bortis, D.; Kolar, J.W. Scaling and balancing of multi-cell converters. In Proceedings of the 2014 International Power Electronics Conference (IPEC-Hiroshima 2014-ECCE ASIA), Hiroshima, Japan, 18-21 May 2014; pp. 2079-2086.

22. Lamorelle, T.; Andreta, A.; Lembeye, Y.; Crébier, J.; Podvin, J. Design level power electronics building block: Industrial framework for DC-DC conversion. In Proceedings of the 2018 IEEE International Conference on Industrial Technology (ICIT), Lyon, France, 20-22 February 2018; pp. 670-675. [CrossRef]

23. Kerachev, L.; Lembeye, Y.; Andreta, A.; Crebier, J. Generic Approach for Design, Configuration and Control of Modular Converters. In Proceedings of the PCIM Europe 2017, International Exhibition and Conference for Power Electronics, Intelligent Motion, Renewable Energy and Energy Management, Nuremberg, Germany, 16-18 May 2017; pp. 1-8.

24. NIST/SEMATECH. e-Handbook of Statistical Methods. Available online: http://www.itl.nist.gov/div898/handbook/ (accessed on 10 March 2019).

25. Giri, R.; Choudhary, V.; Ayyanar, R.; Mohan, N. Common-duty-ratio control of input-series connected modular DC-DC converters with active input voltage and load-current sharing. IEEE Trans. Ind. Appl. 2006, 42, 1101-1111. [CrossRef]

26. James, G.; Witten, D.; Hastie, T.; Tibshirani, R. An Introduction to Statistical Learning; Springer: New York, NY, USA, 2013 ; Volume 103.

27. Richardson, R.R.; Osborne, M.A.; Howey, D.A. Battery health prediction under generalized conditions using a Gaussian process transition model. J. Energy Storage 2019, 23, 320-328. [CrossRef]

28. SAli, H.; Heydarzadeh, M.; Dusmez, S.; Li, X.; Kamath, A.S.; Akin, B. Lifetime Estimation of Discrete IGBT Devices Based on Gaussian Process. IEEE Trans. Ind. Appl. 2018, 54, 395-403.

29. Andreta, A.; Lembeye, Y.; Villa, L.L.; Crebier, J.-C. Statistical Modelling Method for Active Power Components Based on Datasheet Information. In Proceedings of the PCIM Europe 2018, International Exhibition and Conference for Power Electronics, Intelligent Motion, Renewable Energy and Energy Management, Nuremberg, Germany, 5-7 June 2018; pp. 1-7.

30. Rasmussen, C.E.; Williams, C.K.I. Gaussian Processes for Machine Learning; 3. Print; MIT Press: Cambridge, MA, USA, 2008.

31. EEMB. Lithium-Ion Battery Datasheet-LIR18650 $2600 \mathrm{mAh}$. Available online: https://www.eemb.com/public/image/ download/LIR18650(2600).pdf (accessed on 20 January 2021). 